Gerión. Revista de Historia Antigua

ISSN: 0213-0181

http://dx.doi.org/10.5209/GERI.63871

\title{
Adriano contra Bar Kosiba, apóstata del helenismo ${ }^{1}$
}

\author{
Pedro Giménez de Aragón Sierra²
}

Recibido: 20 de mayo de 2018 / Aceptado: 9 de enero de 2019

Resumen. La Carta de Simón ben Kosiba a Josué ben Galgula nos habla de su política religiosa y la Carta de Soumaios de su política lingüística y cultural. En este artículo se relaciona la ideología antihelenística de Bar Kosiba con el filohelenismo de Adriano y su política religiosa, en pleno proceso de separación de judaísmo y cristianismo. Precisamente en esta época apareció el neologismo "christianismós" en las Cartas de Ignacio de Antioquía.

Palabras clave: cartas de Bar Kosiba; Adriano; Ignacio de Antioquía; judaísmo; cristianismo.

\section{[en] Hadrian against Bar Kosiba, Apostate of Hellenism}

\begin{abstract}
The Letter of Simeon ben Kosiba to Jesus ben Galgula tells us about his religious policy and the Letter of Soumaios tells us about his linguistic and cultural policy. In this essay the anti-Hellenistic ideology of Bar Kosiba is connected with Adriano's philo-Hellenism and with his religious policy, in the process of separation from Judaism and Christianity. Just at this time appeared the neologism "christianismós" in the Letters of Ignatius of Antioch.
\end{abstract}

Keywords: Bar Kokhba Letters; Hadrian; Ignatius of Antiochia; Judaism; Christianism.

Sumario: 1. Textos. 2. Contexto. 3. Interpretación. 4. Referencias bibliográficas.

Cómo citar: Giménez de Aragón Sierra, P. (2019): Adriano contra Bar Kosiba, apóstata del helenismo, en Gerión 37/1, 117-148.

\footnotetext{
1 Este estudio se ha realizado dentro del proyecto "Adriano y la integración de la diversidad regional. Una perspectiva histórica e historiográfica" (HAR2015-65451-C2-1-P MINECO/FEDER). Agradezco al profesor J. M. Cortés Copete sus sugerencias. Yo soy el único responsable de los errores que mi trabajo pudiera contener.

2 Universidad Pablo de Olavide (Sevilla). pgimsie@upo.es
} 


\section{Textos}

\subsection{Carta de Soumaios (P. Yadin 52)}

$1 \Sigma o v[\mu \alpha \tilde{i}] \circ \varsigma^{\prime} \operatorname{I} \omega v \alpha \theta \tilde{\eta} 1$

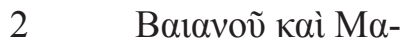

$3[\sigma] \alpha \beta \alpha \dot{\lambda} \alpha \chi \alpha i ́ \rho \varepsilon ı v$.

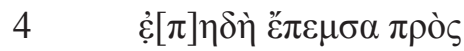

5 v $\mu \tilde{\alpha} \varsigma \mathrm{A}[\gamma] \rho i ́ \rho \rho \alpha v ~ \sigma \pi \mathrm{ov}-$

$6 \delta[\alpha ́ \sigma \alpha] \tau \varepsilon \pi \varepsilon \dot{\varepsilon} \mu \sigma \varepsilon \mu \mathrm{ol}$

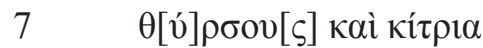

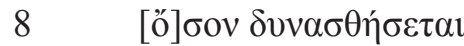

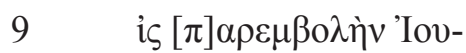

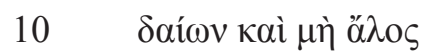

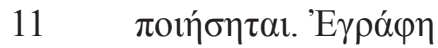

$12 \delta[\grave{\varepsilon}]^{\mathrm{C}} \mathrm{E} \lambda \eta v i \sigma \tau \grave{~} \delta$ ì̀

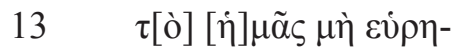

$14 \kappa[\varepsilon ́] v \alpha i{ }^{\circledR} \mathrm{E} \beta \rho \alpha \varepsilon \sigma \tau i$

$15 \dot{\varepsilon}[\gamma \gamma \rho] \alpha \dot{\varphi} \varphi \alpha \sigma \tau \alpha 1$. Aủंòv



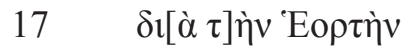

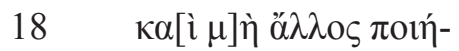

$19 \sigma \eta[\tau \alpha] \mathrm{r}$

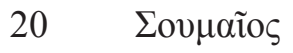

21 है $\rho \omega \sigma o$

\subsection{Carta de Simón ben Kosiba (MUR 43)}
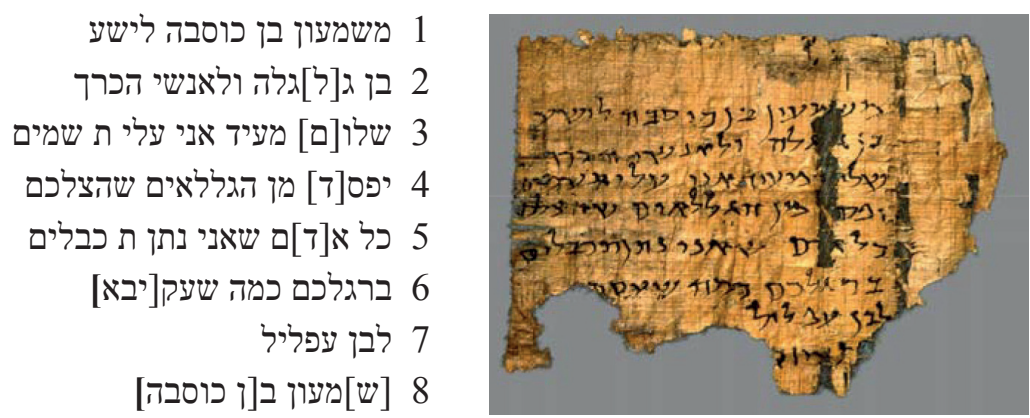


\subsection{Traducción (entre paréntesis el número de línea del texto original)}

Carta de Soumaios (P. Yadin 52):

(1) Soumaios a Jonatán (2) hijo de Baianos y a Ma-(3)sabala, saludos.

(4) Después de que he enviado hacia (5) vosotros a Agripa, apre-(6)suraos en enviarme (7) tirsos y cidras (8) cuanto antes sea posible (9) al campamento fuerte de los Ju-(10)díos y no de otro modo (11) sea efectuado. Ha sido escrita (12) por cierto en griego ya que (13) no se ha hallado ni encon-(14)trado quien en hebreo (15) la escribiese. Vosotros personalmente (16) enviadlos pronto (17) por la Fiesta (18) y no de otro modo pro-(19)cedáis.

(20) Soumaios.

(21) ¡Sed fuertes!

\section{Carta de Simón ben Kosiba (MUR 43):}

(1) Simón ben Kosiba a Josué (2) ben Galgula y a los hombres de la fortaleza.

(3) ¡Shalom! ¡Pongo por testigo al Cielo Superior! (4) Como sea dañado uno de los galileos que están a vuestro lado (5) os pongo a todos ahora mismo grilletes (6) en vuestros pies, como Áquiba hizo (7) a Ben Aflil.

(8) Simón ben Kosiba.

Estas dos cartas pertenecen al corpus del epistolario de Bar Kosiba, líder de la rebelión judía contra el emperador Adriano entre 132 y 136 d.C. ${ }^{3}$ La de Soumaios fue escrita en griego helenístico sobre papiro, la de Simón ben Kosiba en hebreo con caligrafía postherodiana. Esta última fue encontrada en 1952 en una cueva de Wadi Murabba'at, mientras que la de Soumaios fue hallada en la "cueva de las cartas" de Nahal Hever, explorada por primera vez en 1954 por Aharoni y excavada sistemáticamente en 1961-3 por Yadin. ${ }^{4}$

La Carta de Soumaios es un texto de un escriba poco profesional con múltiples

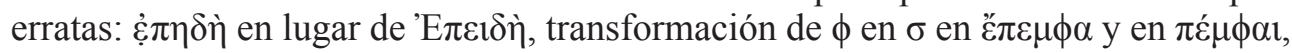

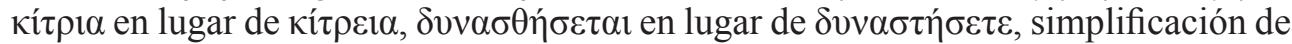

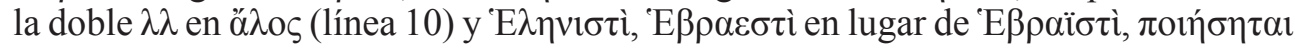

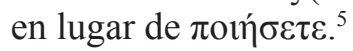

La Carta de Simón ben Kosiba es importante en primer lugar porque en ella aparece el nombre verdadero del líder rebelde y probablemente su firma autógrafa. ${ }^{6}$ Fue

\footnotetext{
En adelante, y mientras no se indique lo contrario, se entiende que todas las fechas citadas son d.C.

4 Milik 1953, 276-294; Lifshitz 1962, 240-258. El corpus completo consta de 28 cartas halladas en tres cuevas: 16 escritas en hebreo procedentes de Wadi Murabba'at (MUR 42-52, de las cuales MUR 49-52 son sólo fragmentos), 4 en hebreo de Nahal Hever (P. Yadin 49, 51, 60 y 61) y una en hebreo de Nahal Se'elim (Xhev/Se 30), 9 en arameo procedentes de las cuevas de Nahal Hever y Nahal Se'elim (P. Yadin 50, 53-58, 62 y 63 ) y 3 escritas en griego procedentes de Nahal Hever (P. Yadin 52, 59 y 64). Sólo recientemente se ha publicado la totalidad de las cartas de Nahal Hever por el equipo Yadin et alii 2002. Más recientemente aún se ha publicado en italiano una colección bastante completa, reuniendo cartas de las tres cuevas, cf. Martone 2012. En español tan sólo se han publicado las cartas en arameo: Alonso - Alarcón 2006, 23-54.

Martone 2012, 70-74.

6 Respecto a la firma, véase Milik 1961, 159-161. Respecto al nombre, la vocalización de las letras hebreas כוסבה, $k v s b h$, la conocemos gracias al papiro griego P. Yadin 59 de la "cueva de las cartas": $\chi \omega \sigma ı \beta$. Hasta el descubrimiento de esta carta se conocía su nombre por los textos cristianos que suponían un ensalzamiento de su figura como Mesías por parte de sus seguidores modificando su nombre en Bar Kokhba, "Hijo de la Estrella", y por los textos rabínicos que considerándolo un falso Mesías - dado su fracaso- degeneraban su nombre en Bar
} 
escrita, según el padre Milik, por un profesional "de chancellerie", ${ }^{7}$ tema sobre el que discrepan Birnbaum y Martone, dado el carácter predominante del elemento cursivo y la imprecisión gráfica. ${ }^{8}$ Paleográficamente, se han planteado debates respecto a varias palabras.

En primer lugar, sobre הכרך (hkrk, "fortaleza") de la línea 2, que según Milik9 הברך, הבר, (hbrk, "Ha Baruk"), correspondiente al romano Cafar Baraika, actual pueblo de Bani Naim, cerca de Hebrón, a mil metros de altitud. Recientemente SarAvi, aceptando la lectura de Milik, ha propuesto identificar el topónimo con Khirbet Bureiku, localizado en el área del kibbutz Migdal Oz, en el camino entre Jerusalén y Hebrón. ${ }^{10}$ Pero es difícil explicar qué hace en el Mar Muerto una carta dirigida a la zona de Hebrón, al otro lado de las montañas. Además, el análisis paleográfico es claro: observando la fotografía de la carta detenidamente se aprecia una gran diferencia entre la הכרך y la de la nombre de Ben Kosiba, en la línea 1. Por tanto, es más lógico suponer que el autor escribe la palabra "fortaleza" -tal como consideraron entre otros Birnbaum, Yeivin y el propio Milik en su primera traducción de la carta-, ${ }^{11}$ refiriéndose a la sede donde Josué ben Galgula ejercía de comandante de campo, cargo que sabemos detentaba por la carta 42 de Wadi Murabba'at. ${ }^{12}$

En segundo lugar, se ha planteado discusión sobre la primera palabra de la línea 4: ¿comienza por 1 o ' $(v$ o $y)$ ?, ¿la tercera letra es o o p $(s$ o $q)$ ?, ¿cuál es la letra que falta por la laguna producida como consecuencia de la mancha negra que cruza la carta de arriba abajo por la parte derecha? ${ }^{13}$ Sin embargo, aquí el debate ha sido menor y la mayoría se inclina por la reconstrucción con una ד de la palabra פסד (ypsd), lógica por el contexto aunque la conjugación del verbo פסד (psd, "dañar") en niphal ("ser dañado") sea rara. Por otra parte, la alternativa por la que se inclina Birnbaum, que defiende la qof frente a la samek, יפקד (ypqd, "ser desaparecido"), no supone un cambio importante de significado. ${ }^{14}$

Más complicado aún es decidir sobre la última palabra de la línea 6, que Birnbaum interpreta como el nombre "Áquiba” (precedido del relativo), puesto que no sólo hay una dificultad paleográfica con la samek y la qof, sino que el resto de las letras no están completas como consecuencia de un corte en la parte inferior del papiro. ${ }^{15}$ Otro aspecto polémico, a pesar de la claridad de las letras en la línea 7, es su traducción

Kozba, "Hijo de la Mentira" (Nötscher 1961, 449-451). Un argumento a favor de la utilización política por parte de los rebeldes de la similitud entre Ben Kosiba y Ben Kokhba es el hecho de que aparezcan estrellas en las monedas acuñadas por orden del líder judío (Mildenberg 1984, 31-68).

$7 \quad$ Benoit et alii 1961, 159.

8 Birnbaum 1954, 30-31; Martone 2012, 42-44. Así por ejemplo, el escriba de MUR 44 no sólo escribe de forma menos cursiva que el de MUR 43, sino que vocaliza más, como por ejemplo en el nombre del destinatario ' בן גלוע בן גלגולה, Yšh ' destacarse, por ejemplo, la imprecisión de la $\pi(h)$ que parece una $\Pi(h)$.

Benoit et alii 1961, 160.

10 Sar-Avi 2002.

11 Milik 1953, 278; Birnbaum 1954, 24; Yeivin 1955, 95-108.

12 MUR 42.2.

13 Aunque la forma de cerrar la samek por abajo sea algo triangular, prestándose a confusión con qof, si observamos la samek del apellido de Ben Kosiba en la línea 1 vemos que es prácticamente idéntica a esta de la línea 4.

14 Birnbaum 1954, 25-27. Otra reconstrucción posible es la de Theicher 1953, 133-134, n. 126.

15 Milik había transcrito שעסיתי ( ${ }^{\prime}$ s'styty), y ambos traducen: "como yo hice", atribuyendo al propio Ben Kosiba el haber puesto cepos a Ben Aflil. Pero, dado el estado del papiro, ambas reconstrucciones son hipotéticas. En cualquier caso, no es posible tomar la lectura de Birnbaum como una prueba histórica de la participación activa de Áquiba en el liderazgo de la rebelión, con poder de mando. 
que algunos consideran como nombre propio, Ben Aflil o Aflul, y Martone interpreta como un sobrenombre "a chi se è comportato in modo impudente". ${ }^{16}$ En cuanto al lenguaje, se trata de un hebreo similar al de los textos no literarios de Qumrán, con errores como la confusión de las guturales. ${ }^{17}$ También es llamativo el uso, tanto en la línea 3 como en la línea 5, de la ת como forma apocopada de la partícula de acusativo את, un uso coloquial de posible influencia neopúnica que demuestra que el hebreo aún estaba vivo en la época. ${ }^{18}$ Finalmente, expresiones como "pongo por testigo al Cielo Superior”, מעיד אני עלי ת שמים ( $m$ 'yd any 'ly $t$ šmym, línea 3), nos acercan a la literatura rabínica. ${ }^{19}$

\section{Contexto}

Tras la destrucción de Jerusalén por Tito en el 70 y el estacionamiento en sus ruinas de la Legión X Fretensis en torno al 74, después de la toma de Masadá, su distrito y el desierto de Judea quedaron despobladas de judíos, como describía Plinio el Viejo en torno al 77. ${ }^{20}$ Los epígrafes hallados en Jerusalén correspondientes al período 74132 están escritos en latín. ${ }^{21}$

En primavera del 115 Trajano conquistó el reino judío de Adiabene y a finales del verano de aquel año estalló un conflicto entre judíos y griegos en Alejandría. Al parecer, Trajano había favorecido a los judíos egipcios, sin embargo el prefecto de Egipto, Rutilio Lupo, intervino militarmente contra ellos y promulgó un edicto el 13 de octubre ordenando paz en tanto llegaba un juez especial enviado por Trajano. ${ }^{22}$ Pero el emperador estaba entonces en plena conquista de Mesopotamia (Ctesifonte caería en enero de 116 y en primavera alcanzaría el Golfo Pérsico), por lo que probablemente no pudo atender dicha petición, y como consecuencia estalló una gran rebelión judía en Egipto, Cirenaica y Chipre, que se extendió a la recién conquistada Mesopotamia y a la propia Judea. Trajano encargó al general mauritano Lusio Quieto que sofocara la rebelión judía mesopotámica y luego lo nombró gobernador de Judea con rango consular y puso una segunda legión en la provincia bajo su mando, la VI Ferrata, acantonada en el norte. ${ }^{23}$

Adriano, que había sido nombrado gobernador de Siria por Trajano entre 115 y 117 , consiguió que en su provincia no se produjera ninguna rebelión judía, aunque es posible que durante su proconsulado fueran ejecutados en Laodicea de Siria los banqueros judíos Pappo y Luliano. Las fuentes talmúdicas y rabínicas, sin embargo, atribuyen estas muertes a Trajano, que aún era el emperador. ${ }^{24} \mathrm{El}$ origen alejandrino de Luliano quizás implicase una conexión con la rebelión judía en Egipto. Inmedia-

\footnotetext{
16 Coincido con Yeivin 1955, 106, en que es Aflil, con ', y no Aflul, con ו. Respecto a la interpretación de Martone 2012, 42-44.

17 Al final de la línea 4, en la construcción שהצלכם (šslkm, "que están a vuestro lado"), después del pronombre relativo $\boldsymbol{w}(\breve{s})$, aparece una $(h)$ en lugar de una ('), que sería lo correcto. Qimron 1986, 25.

18 Martone 2012, 43.

19 Talmud de Babilonia Jebamot 67A y 'Arakin 67b.

20 Plin. HN 5.69-73.

21 Isaac 2004, 139-151.

22 Papiro CPJ 435.

23 Respecto al debate sobre la existencia de rebelión en Judea en época trajanea, véanse, a favor, García 1993, 144, y, en contra, Perea 2001, 323-324, siguiendo a Sartre, 1991, 383, y 1997, 364.

24 Horbury 2014, 264-268.
} 
tamente después, en cuanto Adriano fue nombrado emperador, demostró su conocimiento de la mentalidad judía: sus dos primeras órdenes -en agosto de 117- fueron la evacuación de Mesopotamia, Asiria y Armenia Mayor, que Trajano ya había entregado a reyezuelos vasallos antes de morir, y la destitución de Lusio Quieto como gobernador de Judea, enviando a la provincia rebelde a su hombre de confianza en temas militares, Marcio Turbo, ciudadano de Epidauro -la ciudad griega de la costa dálmata- que había ejercido con Trajano el mando sobre la flota de Miseno y la Prefectura de Egipto a principios de 117 sustituyendo a Rutilio Lupo, donde consiguió primero pacificar a los judíos. ${ }^{25}$ En Judea, las tropas mauritanas de Lusio Quieto habían reprimido con extrema dureza a la población, por lo que Adriano envió a Egipto a Rammio Marcial para que Marcio Turbo pudiera hacerse cargo de Judea, donde tuvo de nuevo éxito en sus negociaciones, con lo que Adriano fue tratado como un libertador por los judíos al principio de su imperio.

De hecho, el Midrás Génesis Rabbá ${ }^{26}$ indica que la primera intención de Adriano fue reconstruir el Templo de Yahvé en Jerusalén, en tiempos del rabino Josué ben Hananías, relacionado también con la Guerra de Quieto, denominada en las fuentes talmúdicas "Guerra de Qitos". Aunque algunos dudan de la historicidad de esta fuente del siglo IV, que atribuye a los samaritanos el cambio de opinión del emperador, otros como Boyarin, Bazzana o Capponi consideran que este Midrás debe basarse en una fuente anterior a la guerra (de lo contrario sería inconcebible una visión positiva del emperador), especialmente teniendo en cuenta que en el 117 Adriano visitaría Jerusalén camino de Alejandría. ${ }^{27}$ Todavía más innovadora es, en este sentido, la interpretación de Peleg, que considera que en 118 el emperador inició la reconstrucción del Templo y pactó con Bar Kosiba como nuevo Nasí de Israel datando así en ese año la "Redención de Israel" de los documentos del Mar Muerto. El enfrentamiento surgiría, según él, a partir de 130. Ese año comenzaría la reconstrucción de Jerusalén, como ha demostrado Baker, que ha dado pruebas de la estancia de Adriano en 129$130 .^{28}$ Probablemente hasta entonces sólo se hubiesen realizado tareas de limpieza y cimentación de las antiguas ruinas de Jerusalén y debió ser durante su estancia en la ciudad cuando Adriano y sus arquitectos presentasen los planos de la colonia. Sin embargo, entre 117 y 130, la situación en Jerusalén debió ser de transición o normalización. Probablemente, en esos años algunos judíos y cristianos comenzaron a asentarse en los alrededores de la ciudad. Ese ambiente transmiten fuentes cristianas del siglo IV que narran cómo Adriano, durante su estancia en la ciudad en el 130, vio que al sur del campamento romano, cerca de la puerta de Sión, había unas pocas casas y una pequeña iglesia cristiana construida en el lugar del Cenáculo. ${ }^{29}$ La misma situación se deduce del pasaje de la Misná en el que Josué ben Hananías recomienda realizar sacrificios en las ruinas del Templo y pagar los diezmos, porque lo que se consa-

25 Syme 1962, 87-96, plantea la posibilidad de que Turbo fuera el centurión primus pilus de la Legión II Adiutrix en que Adriano comenzó su carrera militar como tribuno laticlavo en 95-96. Los jóvenes nobles romanos solían apoyarse en suboficiales de larga experiencia para ejercer como oficiales.

26 Ber. R. 64.10 (sobre Gn 26.28-29): "In the days of Joshua ben Hananiah, the empire decreed that the house of the sanctuary should be rebuilt. Pappus and Lulianus set up banks from Acco to Antioch, and supplied those who came up from the Exile..." (traducción de Horbury 2014, 302).

27 Boyarin 1994; Bazzana 2010, 102-109; Capponi 2010, 489-501.

28 Peleg 2011, 369-383; Baker 2012, 157-167.

29 Epifanio Mens. et Pond. 14; con paralelos en el Itinerarium Burdigalense 592-593, del año 333, y en el tardío Diálogo de Timoteo y Áquila. 
gró fue el lugar, no el edificio. ${ }^{30}$ Conviene tener en cuenta, también, que el rabino Josué ben Hananías, a pesar de oponerse a la helenización, era bastante moderado en lo político, como mostraba el pasaje ya citado del Midrás Génesis Rabbá, calmando a los judíos partidarios de la rebelión en la época de la Guerra de Qitos.

La imagen positiva de Adriano entre los judíos desde 117 hasta 132 se aprecia también en el V Oráculo Sibilino, que lo calificaba de "hombre excelente que comprende todas las cosas" y lo equiparaba a Nerva, que suprimió el Fiscus Iudaicus, frente a los belicistas Vespasiano y Trajano. ${ }^{31}$ De hecho, hay un papiro que demuestra su política a favor de los judíos de Alejandría tras la Guerra de Qitos: el Papiro 158 del CPJ, en que se narran las Actas de los mártires alejandrinos Paulo y Antonino. ${ }^{32}$

No es real, por tanto, la versión de aquellos historiadores judíos que consideran que la política de Adriano hacia Judea estuvo condicionada por la mala impresión que tuvo de ellos cuando fue nombrado gobernador de Siria y se produjo la Guerra de Qitos, hechos que provocarían su "indiferencia e incluso hostilidad hacia las religiones orientales y el judaísmo en particular" ${ }^{\prime 3}$. Frente a ellos, otros historiadores israelíes, como Mor, han defendido que la política adrianea no era antijudía, sino orientada a servir al bien del Imperio y de la provincia de Judea como parte integrante del mismo. ${ }^{34}$

Sin embargo, no todos los rabinos estarían de acuerdo con la política de Adriano respecto a Judea, ya que eran muchos los que rechazaban la helenización. La Misná menciona el rechazo de algunos rabinos a la enseñanza del griego:

Con la Guerra de Vespasiano se prohibieron la corona del novio y los tambores. Con la Guerra de Qitos se prohibió el uso de las coronas a las novias y que se enseñara griego al propio hijo. En la última guerra se prohibió que la novia saliera bajo baldaquino por medio de la ciudad. Pero nuestros doctores permitieron que la novia saliera con el baldaquino por medio de la ciudad. ${ }^{35}$

El Talmud de Jerusalén incluye una baraíta que atribuye al rabino Josué ben Hananías, discípulo de Johanán ben Zakay, el fundador de la Escuela o Sanedrín de Yamnia, la prohibición de enseñar el griego durante la Guerra de Qitos. ${ }^{36}$ Se trata del mismo Josué ben Hananías mencionado en el Midrás de la reconstrucción del Templo y que en otros dos pasajes del Midrás Génesis Rabbá aparecía reunido con Adriano. ${ }^{37}$ El Talmud de Babilonia incluye otra baraíta que atribuye al rabino Ismael la prohibición de enseñar la filosofía griega. ${ }^{38}$ Los rabinos de la Casa de Hilel, sin embargo, eran

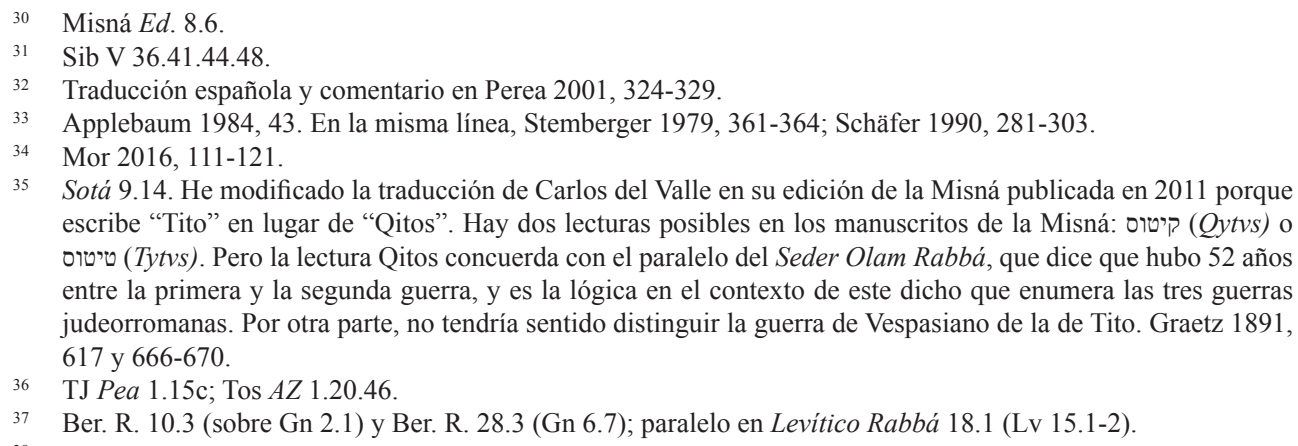
escribe "Tito" en lugar de "Qitos". Hay dos lecturas posibles en los manuscritos de la Misná: קיטוס (Qytvs) o טיטוס (Tytvs). Pero la lectura Qitos concuerda con el paralelo del Seder Olam Rabbá, que dice que hubo 52 años entre la primera y la segunda guerra, y es la lógica en el contexto de este dicho que enumera las tres guerras judeorromanas. Por otra parte, no tendría sentido distinguir la guerra de Vespasiano de la de Tito. Graetz 1891, 617 y 666-670.

36 TJ Pea $1.15 \mathrm{c}$; Tos $A Z 1.20 .46$.

37 Ber. R. 10.3 (sobre Gn 2.1) y Ber. R. 28.3 (Gn 6.7); paralelo en Levítico Rabbá 18.1 (Lv 15.1-2).

38 TB Men $99 \mathrm{~b}$. 
menos rígidos al respecto $\mathrm{y}$, al igual que se negaron a implantar la prohibición del baldaquino para las novias mencionada en el pasaje misnaico citado, tuvieron una mayor tolerancia respecto al uso del griego. Gamaliel II, condiscípulo de Josué y sucesor de Johanán ben Zakay en la presidencia de la Escuela de Yamnia, enseñaba la Torá a 500 alumnos y el griego a otros 500; y Yehudá Ha Nasí recomendaba leer la Torá en hebreo o en griego, pero no en arameo. ${ }^{39}$ Había, pues, división entre los rabinos respecto al uso del griego durante la época de Adriano, un emperador que no sólo amaba la lengua griega, sino todo lo relacionado con el mundo helénico.

La helenización del Imperio Romano por parte de un hispano que presumía de proceder de un linaje griego de Hadria, en la costa adriática de Italia, ${ }^{40}$ debe situarse en el contexto de la crisis producida en el Imperio por la rebelión judía de los años 115-117. El hecho de que la soberanía romana peligrase en cinco provincias al mismo tiempo debió provocar una reacción importante en Adriano, consciente no sólo de que una continuación en la expansión imperial podría producir la fractura del Imperio, sino también de que antes de pensar en nuevas expansiones convenía consolidar lo adquirido mediante una política que potenciase la identidad romana entre los habitantes de las distintas provincias. Y esto, que en su propia patria había sido sencillo por un profundo proceso de romanización al igual que en la mayor parte de las provincias occidentales, sólo era posible en Oriente mediante la identificación entre romanización y helenización.

La helenización del Imperio de Adriano es un hecho indiscutible que se manifiesta no sólo en el arte neoático que patrocina y en las ciudades que construye por todo el Imperio, sino también en todos los aspectos de su política cultural y muy especialmente en su política religiosa. ${ }^{41}$ Aparte de algunas concesiones tradicionalistas a la cultura latina, como la revalorización de las figuras de Rómulo y Numa Pompilio en el año 121 mediante la celebración del Saeculum, toda la política religiosa adrianea estuvo inspirada por el helenismo como factor capaz de unificar las civilizaciones de todo el Imperio, desde la helenizada Cádiz hasta el Éufrates, bajo una misma identidad religiosa, entendida no sólo como griega, sino en el más puro sentido helenístico, como integración de las culturas autóctonas en la helénica mediante un sincretismo abierto a nuevos cultos.

Destaca, en primer lugar, el puesto honorífico que otorgó a la religión griega, fomentando no sólo el culto de Apolo (dios de la anfictionía de Delfos, que presidió), Hércules (vinculado a la ciudad de su madre, Cádiz), Diana (vinculada a su patria, Itálica, donde practicaba la caza en su juventud), las diosas eleusinas Démeter y Core (en cuyos misterios fue iniciado hasta el grado máximo) y, por supuesto, Zeus Olímpico (cuyo gigantesco templo ateniense, iniciado por Pisístrato en el siglo VI a.C., terminó e inauguró siete siglos después). Si en 124 reformó la anfictionía délfica para incrementar la representación de Atenas y Esparta frente a la hiperrepresentada Tesalia, convirtiéndose en una suerte de nuevo Filipo, hegemon de la Hélade y patrono de Delfos, en 130-131 creó el Panhelenio, unos juegos panhelénicos que integraban a ciudades de todo el Mediterráneo en el helenismo. ${ }^{42}$

39 Sotá 49b, BQ 82b y 83b; Git. 58A; TJ Taan. 4.8.69a. LmR 2.2.52b; Tos. Sotá 15.322. Hadas-Lebel 2006, $271-274$.

40 Idea errónea porque los arqueólogos han demostrado que la Adria prerromana (actual Atri) era una ciudad sícula-ilírica cuyo nombre procedía del dios sículo Hadranus (Cusumano 1992).

41 Galimberti 2007, 123-184.

42 Gordillo 2012. 
Ahora bien, como hiciera Alejandro, el hijo de Filipo, no sólo difundió los cultos a los dioses griegos, sino que también fomentó la integración de los cultos extranjeros, especialmente de los egipcios. Explicaba Arriano de Nicomedia que Alejandro contribuyó a la integración del culto a Isis desde la fundación de Alejandría de Egipto. Adriano hizo todavía más. ${ }^{43}$ En esta línea sincretista hay que entender la divinización de Antinoo y la imposición de su culto no sólo en Antinoopolis, a orillas del Nilo (ciudad fundada también por interés comercial, al trazar desde ella una ruta directa al mejor puerto del Mar Rojo), sino también en Roma, con el obelisco del Piceno, y en el Canopus de la Villa de Tívoli. La heroización de Antinoo hace más comprensible la divinización de los emperadores y su familia. Adriano pretendía que los habitantes de su Imperio Romano helenizado admitiesen como posible en sus tiempos lo que había ocurrido en la edad dorada de los héroes míticos: que un hombre se hiciera dios.

En la misma línea hay que situar la política lingüística neoática de Adriano. ${ }^{44}$ Frente a la lengua griega coloquial o koiné, fomentó una lengua griega literaria de marcado arcaísmo, caracterizada por léxico, morfología y sintaxis inspirados en las formas áticas de los siglos V-IV a.C. El propio Arriano, amigo de Adriano -con el que compartió las enseñanzas del filósofo estoico Epicteto y participó en el Senado y en el gobierno de las provincias-, escribía en koiné cuando redactaba sus apuntes de las Diatribas de Epicteto y en lengua ática en el resto de sus obras. ${ }^{45} \mathrm{El}$ aticismo fue el lenguaje de la Segunda Sofística, vinculada con Adriano.

Por último, hay que señalar que Adriano llevó a cabo una política de restauración de las provincias que se aprecia no sólo en los magníficos relieves de su Hadrianeum romano, dispersos actualmente entre los museos Capitolino, Massimo y Napolitano, sino también en sus emisiones monetales. Las monedas de Adriano son un claro ejemplo de política propagandística y en ellas figuraban leyendas como Restitutor Siciliae, Restitutor Africae o Restitutor Iudaeae. ${ }^{46}$ Frente a la Iudaea Capta de los Flavios, en las monedas de Adriano aparece una Judea dignificada y libre. Dicha política consistió, como en todas las provincias, en la restauración y construcción de edificios en las ciudades principales, así como en la creación de nuevas ciudades. Esta política de obras públicas supuso poner en circulación una gran cantidad de moneda (proveniente de los tesoros adquiridos por las conquistas de Trajano), así como el incremento del trabajo y la demanda en todas las provincias del Imperio, es decir, una política monetaria expansiva, que produjo un considerable crecimiento económico.

Entre 117 y 130, Adriano llevó a cabo una importante política de urbanización de Galilea, reconstruyendo y rebautizando Séforis como Diocesarea, la ciudad plenamente romanizada que los arqueólogos han rescatado con sus mosaicos y su arquitectura clásica ${ }^{47}$ En Tiberíades construyó un Hadrianeum, quizás en fecha tan tem-

43 No es desinteresado el redescubrimiento de la figura de Alejandro Magno en época de Adriano por parte de uno de sus colaboradores principales en el Senado, en la defensa de las fronteras y en su política cultural. El cosmopolitismo que caracterizó al macedonio también formó parte esencial de la política adrianea. En cuanto al culto de Isis, se difundió más allá de Roma. Ejemplo de ello es el recién descubierto Iseo de Itálica. Muñiz 2006; 2009, 325-341; 2011, 145-153. Véase, también, Bricault 2004.

44 Swain 2003.

45 Floristán 1994, 161-187, y 1995, 91-141.

46 Garzón 1993, 75-85, y 1989, 153-162.

47 Miller 1996, 21-27. 
prana como el 119-120, si relacionamos la noticia de Epifanio ${ }^{48}$ con la moneda de ese año en que aparece Adriano en una cara y un templo de Zeus en la otra. ${ }^{49}$ Las obras realizadas en Séforis y Tiberíades proporcionarían trabajo a la población, reactivando la economía galilea. Los cristianos, por otra parte, tan abundantes en Galilea, no tenían problemas en convivir con los gentiles desde el triunfo del paulinismo, por lo que la convivencia con la antigua población siria y griega de estas dos fundaciones herodianas debió ser mucho más fácil que en época anterior a la primera Guerra Judía. A ellos hay que añadir los veteranos de la Legión VI Ferrata. Recientemente se ha descubierto un interesante mosaico dedicado al Dios Jesucristo por un centurión llamado Gaianus, que es toda una muestra de la situación. ${ }^{50}$ Todo esto explica que la rebelión de Bar Kosiba no tuviera éxito en Galilea. En cuanto a Samaría, la reconstrucción del Templo del Monte Garizim supondría un apoyo tremendo al emperador por parte de los samaritanos. Aunque esto es relativo, ya que el templo se consagraría a Zeus. De hecho, la presencia de samaritanos en Betar indicaría lo contrario. ${ }^{51} \mathrm{En}$ Judea, sin embargo, donde se esperaba la reconstrucción del Templo de Jerusalén, esta medida tendría un efecto contraproducente y quizás debería tenerse en cuenta como una de las causas de la rebelión.

Por otra parte, la interpretación tradicional relativa a la construcción de un templo a Júpiter en el monte del Templo de Jerusalén y la instalación de población pagana en la ciudad como casus belli, debida a Dión Casio, ${ }^{52}$ ha sido seriamente cuestionada últimamente entre otros por Eliav, ${ }^{53}$ que argumenta que las palabras de este pasaje de Dión Casio hay que atribuirlas a los prejuicios antijudíos del monje bizantino Xifilino, que realizó el epítome de la obra del historiador grecorromano, el cual desearía presentar la política de Adriano como un precedente de la política antisemita bizantina. Hay que tener en cuenta, por otra parte, la realidad de que Jerusalén llevaba ya más de medio siglo habitada por los legionarios de la Legión X Fretensis, que practicaban su culto al águila de Júpiter y al cerdo como su emblema legionario, sin que la rebelión estallara desde que se instalaran allí en el año 74. De hecho, entre el 74 y el 130 muchos serían los veteranos legionarios que se asentarían en las ruinas de Jerusalén con sus mujeres e hijos tras licenciarse, constituyendo una población importante que detentaba la ciudadanía romana, por lo que la conversión de la ciudad en colonia hay que entenderla como un modo de dar forma legal a una realidad preexistente. A lo que Adriano sumaría, evidentemente, una gran cantidad de dinero para urbanizar y monumentalizar la ciudad.

Sin embargo, no debemos obviar del todo la forma en que finalmente se construyó Elia Capitolina como casus belli, pero no ya en el modo planteado por Xifilino, sino precisamente en el contrario: la no reconstrucción del Templo de Yahvé debió decepcionar enormemente a los líderes judíos que habían puesto en Adriano todas sus esperanzas de restauración de Israel. Y más cuando la reconstrucción del Templo

48 Panerion 30.12.

49 Belayche 2001, 180.

50 Tepper - Di Segni 2006. El campamento de la legión se situaba en Caparcotna (Kefar Otnai), en el Valle de Jezreel, cerca de Tel Megiddo.

51 A pesar de que las fuentes rabínicas acusan a un samaritano de traicionar a los sitiados de Betar, como dice Aharón Oppenheimer 1980, 72, el hecho de que hubiera samaritanos en la ciudad indica que hubo división respecto al apoyo a judíos o romanos.

52 D.C. Epit. Xiph. 59.12.

53 Eliav 1997, 125-144. 
del Monte Garizim se hizo efectiva. En este sentido, tampoco debemos de rechazar la historicidad y las razones del pasaje mencionado del Midrás Génesis Rabbá, que tiene un importante apoyo en la Carta de Bernabe ${ }^{54}$ coetánea a los hechos. Me atrevería incluso a apuntar que no serían precisamente los samaritanos los más interesados ni beneficiados por la no reconstrucción del Templo. Sin duda los samaritanos se alegrarían, pero no sólo ellos. La Carta de Bernabé nos muestra a la comunidad cristiana profundamente preocupada por el hecho de que los romanos estuvieran ayudando a reconstruir el Templo. Los samaritanos no competían con los judíos por captar seguidores, los cristianos sí. Esto no significa, como se ha dicho por parte de algunos exégetas, que Bernabé aludiese irónicamente a la construcción de Elia Capitolina con sus templos paganos. No. La especulación teológica acerca del carácter sacerdotal de Jesucristo es una prueba de lo que realmente preocupaba al autor: la apostasía por parte de los judeocristianos palestinos decepcionados con el incumplimiento de la profecía de la Segunda Venida de Cristo (que debía haberse producido en la generación de los apóstoles) ${ }^{55}$ y la pérdida de sentido del argumento en beneficio del cristianismo sobre la destrucción del Templo profetizada por el mismo Jesús como castigo por la participación del Sumo Sacerdote y el Sanedrín en su ejecución.

Al hecho de negarse a reconstruir el Templo de Yahvé, se ha añadido como casus belli la supuesta prohibición de la circuncisión mencionada por la Historia Augusta, ${ }^{56}$ apoyando esta fuente en una reflexión de Bernabé que en realidad se sitúa en la línea habitual de la polémica entre el cristianismo paulino y el judaísmo. ${ }^{57}$ Se trata de una cuestión harto discutible. En primer lugar porque los términos usados en esta fuente del siglo IV son mutilare genitalia y no circumcidere, y los prejuicios antijudíos del autor o autores de dicha obra son evidentes. ${ }^{58}$ En segundo lugar, porque las fuentes judías que tratan la cuestión no la plantean de ese modo. Así, en Toseftá Sabat (s. IV), Rabí Yehudá dice que es peligroso circuncidar a un mashukh, es decir, a un judío que se ha reconstruido el prepucio mediante la operación del epispasmos, a lo que responden sus contertulios que muchos lo hicieron en los días de Ben Koziba y no murieron y tienen hijos..$^{59}$ Aunque la noticia parece antigua, no queda claro si se refiere a peligrosidad por incumplimiento del decreto de Adriano o por cuestiones sanitarias. En Midrás Génesis Rabbá un judío es procesado por el gobernador Turno Rufo, por haber circuncidado a su hijo y responde en el juicio que ha obrado conforme a la ley imperial, que está por encima del decreto del gobernador. ${ }^{60}$ Turno Rufo es Quinto Tineyo Rufo, gobernador de Judea a partir del 130, después de Gargilio Antiguo, del que se ha descubierto una importante inscripción en Haifa en enero de 2016. ${ }^{61}$ Rufo fue quien ejecutó al rabino Áquiba según Midrás Mishlei Proverbios 9:2, incluido en

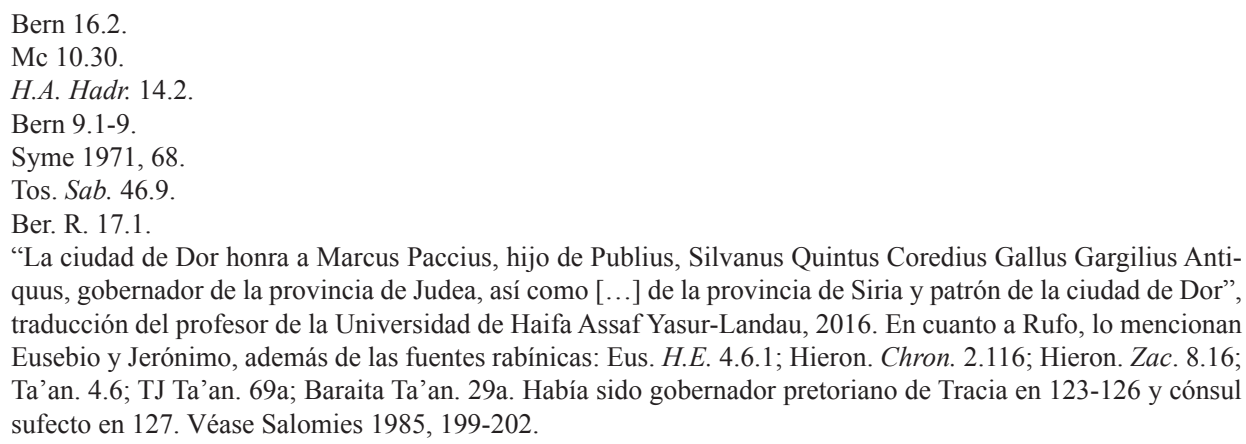


la colección de midrasim a los Salmos publicada en el siglo XI por Natán de Roma. La noticia es coherente con el desarrollo de los hechos, puesto que Rufo gobernó desde 130 hasta 133. Frente a la defensa de la prohibición de la circuncisión como causa principal de la rebelión por parte de Rabello y la negación total de la existencia de dicho decreto por parte de Schäfer, Geiger ha defendido que no fue Adriano, sino Rufo, el que promulgó un decreto prohibiendo la circuncisión, basándose en el hecho de que en la persecución de los cristianos los gobernadores provinciales habían tenido la iniciativa ${ }^{62}$ Pero si relacionamos las noticias judías anteriormente mencionadas con el Rescripto de Antonino Pío sobre la circuncisión, ${ }^{63}$ lo más lógico es concluir que Adriano había prohibido sólo la circuncisión de los gentiles, que Rufo se excedió en dicha aplicación y que Antonino Pío se vio obligado a aclarar cuál era la postura oficial. Lo más probable es que Adriano remitiera a la Lex Cornelia de Sicariis respecto a la posibilidad de circuncidar a un gentil. ${ }^{64}$ De ahí que la fuente del Midrás Génesis Rabbá (quizás el rabino Osaía del siglo III, al que se atribuía la mayor parte de la obra) expusiera la diferencia entre la forma de aplicar la ley por parte de Rufo -prohibiendo también la circuncisión de los hijos de los judíos- y la forma en que fue promulgada la ley por el emperador. En el mismo contexto cabe interpretar la noticia de la Toseftá sobre un mashukh que desea recircuncidarse, puesto que al realizarse la operación del epispasmos el mashukh dejaba de ser judío y, por tanto, se le aplicaba la Lex Cornelia de Sicariis. Es necesario advertir que esta medida perjudicaría al proselitismo judío en beneficio del proselitismo cristiano.

Por otra parte, la rebelión debió tener causas profundas de carácter económico y social generalmente descuidadas al analizar el fenómeno, ${ }^{65}$ que se sumarían a estos tres factores mencionados: la reconstrucción del templo samaritano del Monte Garizim dedicándolo a Zeus, ${ }^{66}$ la no reconstrucción del templo judío de Jerusalén y la prohibición de circuncisión de los prosélitos o limitación del proselitismo rabínico.

En 133 Adriano envió contra Bar Kosiba a su mejor general, Sexto Julio Severo, gobernador de Britania que, curiosamente, había sucedido también a Tineyo Rufo en el consulado sufecto del 127 . No en vano, se trataba de sofocar la única rebelión producida en todo el Imperio contra su política helenística y cosmopolita. A pesar de contar con más tropas, Julio Severo tardó aún dos años en derrotar a los rebeldes. ${ }^{67}$

Frente a los judíos que seguían a los rabinos fariseos, Adriano pudo ver a otro tipo de judíos que no exigían la circuncisión a sus prosélitos, no les exigían tampoco el cumplimiento de las prohibiciones alimenticias, no deseaban la reconstrucción del Templo, y usaban mayoritariamente el griego como lengua de comunicación e incluso de lectura de la Biblia: los cristianos, a los que conocía ya desde el juicio de Flavio Clemente en la corte de Domiciano siendo él sevir turmae equitum romanorum ${ }^{68}$ y a

62 Rabello 1995, 117; Schäfer 1999, 119-132; Geiger 1976, 139-147, y 2016, 497-519.

63 Digesto 48.8.11: Circuncidere iudaeis filios suos tantum rescripto divi Pii permittitur. In non eiusdem religionis qui hoc fecerit, castrantis poena irrogatur.

${ }_{64}$ Esta opción cuadra con lo que argumenta Acerbi respecto a circuncisión y castración en la legislación romana (Acerbi 2003, 75-86). Véase también Cordier 2001, 337-355, y Oppenheimer 2003, 55-67.

65 Mor 2016, 13-105.

66 Evans 2011, 170-182.

67 D.C. Epit. Xiph. 69.13.1-2.

68 Uno de los seis jóvenes de familias senatoriales que capitaneaba los escuadrones de caballeros romanos que desfilaban ante el emperador, el Senado y el pueblo cada 15 de julio. Sólo un tiempo después de esta fecha Adriano sería nombrado tribuno laticlavo de la Legión II Adiutrix, destinada en Aquincum (Budapest), por lo que conoció la ejecución de Flavio Clemente que fue consul suffectus la primera mitad de ese año. 
los que recibió en Atenas en el año 124 (Apologías de Arístides y de Quadrato). Unos judíos "romanizables" o "helenizables", unos judíos que podían integrarse en el proyecto cosmopolita de Adriano junto a sus correligionarios gentiles. A ellos, sí les permitiría residir en la Nueva Jerusalén tras finalizar la guerra en 135 -siempre que abandonasen la práctica de la circuncisión de sus hijos- y allí acudirían cristianos de toda Judea y Transjordania con su primer obispo de origen gentil, llamado Marcos. ${ }^{69}$

\section{Interpretación}

La Carta de Soumaios tiene como objeto solicitar ramas de palmeras y sauces, así como cidras, para celebrar la fiesta de Sucot o de los Tabernáculos, ${ }^{70}$ una de las tres fiestas principales de peregrinación a Jerusalén en tiempos del Segundo Templo, que conmemoraba que Dios hizo habitar en tabernáculos o tiendas a los judíos durante los cuarenta años de peregrinaje en el desierto tras el Éxodo (aunque en Dt 16,13-16, Ex 23,16-17 y Ex 34,22-23 se aprecia un origen agrícola que conmemoraba el fin de la vendimia y la cosecha o recogida de aceituna). Para celebrar esta fiesta el Levítico ordenaba: "tomaréis el primer día el fruto de árboles hermosos, hojas de palmera y ramas de árboles frondosos y sauces de los arroyos, y os alegraréis delante de Yahvé, vuestro Dios, durante siete días". ${ }^{71}$ En época helenística se generalizó la costumbre de utilizar como "fruto hermoso" la cidra, fruta del cidro o citrón (citrus medica), también llamada toronja en castellano (del persa turung, en hebreo אתרוג, trvg), tal como consta en Flavio Josefo al hablar de la fiesta en época de Alejandro Janneo. ${ }^{72}$

Los destinatarios son Jonatán y Masabala, que ejercían el gobierno de la ciudad rebelde de En Guedi. Aparte de la ciudad de Betar (al suroeste de Jerusalén y al noroeste de Belén, sede del gobierno y del ejército de Bar Kosiba -probablemente el "campamento fuerte de los judíos" mencionado en la carta- que controlaba la zona montañosa de Judea), los rebeldes dominaban también el Desierto de Judea y las costas occidentales del Mar Muerto, que se dividía en tres distritos: el septentrional desde Jericó hasta Wadi Murabba'at, el central en torno a En Guedi, y el meridional desde Nahal Se'elim hasta Masadá. ${ }^{73}$ Por tanto, Jonatán y Masabala son dos de los principales líderes rebeldes. El enviado que portaba la carta y las órdenes de Soumaios se llamaba Agripa, nombre romano asumido por la dinastía herodiana y en consecuencia difundido entre sus esclavos y libertos.

El remitente, Soumaios, debía ser un personaje muy importante, dado que ordena con autoridad a estos jefes militares de En Guedi que se encarguen personalmente del envío y no "procedan de otro modo".

Se ha discutido bastante sobre el nombre y la identidad del remitente. Lifshitz defendió la identificación de Soumaios con Simón, como su forma helenizada, y al

69 Eus. HE 5.12.1.

70 Lapin 1993, 111-135.

71 Lv 23.40.

72 I. AI 13.372; aunque curiosamente AI 3.245 menciona en lugar del cidro una manzana del árbol llamado persea. Sobre las características de la cidra se extiende la Misná, especificando que no debe ser robada, ni seca, ni procedente de una ciudad idólatra, ni de un arbusto menor de tres años, ni aquella que tiene una erupción, ni la que no tiene pezón, ni pelada, ni rajada, ni agujereada, ni menor del tamaño de una nuez o un huevo (Suk 3.4-7). El día del golpeo de los ramos de palma -sábado de Sucot- los niños tiraban las palmas y comían las cidras (Suk 4.7).

73 Mor 2016, 455-456. 
autor con Ben Kosiba. ${ }^{74}$ Ciertamente, el lenguaje se asemeja al de las cartas arameas dirigidas por Simón ben Kosiba a los líderes rebeldes de En Guedi, pero su alusión al "campamento fuerte de los judíos" indica que él no lo era. El hecho de que el autor no fuese hebreo no significa que no profesase la religión judía. Dado que se le había encargado la función de conseguir recursos para celebrar la fiesta de Sucot en el campamento principal de los rebeldes, lo más probable es que fuera un prosélito. $\mathrm{Su}$ nombre es más bien la forma helenizada de "Shammai". ${ }^{75}$ Aparece en otro manuscrito del Mar Muerto asociado a un nombre nabateo: Soumaios Abd Aretas, ${ }^{76}$ es decir "siervo de Aretas", nombre propio de los monarcas nabateos. Pudo tratarse de un liberto del rey Aretas IV, fallecido en el año 106. Estos manuscritos del Mar Muerto nos muestran matrimonios mixtos de judíos y nabateos con cierto poder económico que probablemente apoyaron la rebelión, de ahí que sus documentos se hallaran junto a los de los líderes rebeldes de la zona. En conclusión, lo más probable es que se tratara de un prosélito de origen nabateo, quizás incluso fuese el mismo Soumaios Abd Aretas. ${ }^{77} \mathrm{El}$ hecho de que no hubiese encontrado ningún escriba para redactar la carta en hebreo indica que no se encontraba junto a Ben Kosiba en Betar, ya que no es imaginable que en la corte del "Hijo de la Estrella" no se hallase nadie capacitado para escribir en hebreo. Lo más probable es que Soumaios fuera un administrador que estaba de viaje, inspeccionando pueblos y aldeas para recabar recursos necesarios para Betar, a donde se dirigía, y enviase cartas a autoridades de algunos lugares como Jericó, En Guedi o Masadá, para que le mandasen dichos productos al "campamento fuerte de los judíos". El hecho de que este Soumaios, que sólo escribe en griego, fuese de origen extranjero cuadra con la noticia de Dión Casio respecto a la unión de otros pueblos a la rebelión de los judíos. ${ }^{78}$

En cualquier caso, lo realmente interesante de esta fuente es la disculpa del autor a los destinatarios por no haber escrito la carta en hebreo, al no encontrar ningún escriba capaz de hacerlo. Fueran cuales fueran las circunstancias en las que se hallase Soumaios, no deja de ser significativo que no hubiese nadie capaz de escribir en hebreo pero sí lo hubiese capaz de hacerlo en griego (él mismo o un escriba).

La importancia de este hecho es doble: por un lado, es un indicio más del grado de helenización de la Judea del siglo II, por otro lado, es una prueba de la política lingüística de Ben Kosiba. Soumaios tuvo que disculparse porque en la administración rebelde debió existir una norma o costumbre que rechazaba el uso del griego escrito en defensa de la escritura hebrea, que se utilizaba tanto para escribir en hebreo como para escribir en arameo. La arqueología ha demostrado que lo más corriente en la correspondencia privada era el uso de la escritura hebrea en lengua aramea. ${ }^{79}$ La situación de estas tres lenguas en la Judea del siglo II es bastante conocida y existe cierto consenso al respecto: el arameo era la lengua de uso vulgar, mientras que el hebreo seguía siendo la lengua literaria sagrada y la mayoría aprendía a leerlo, aunque no lo usara ni para hablar ni para escribir. El griego, por otra

\footnotetext{
Lifshitz 1962, 243-244. Se basaba en la presencia del nombre griego como testigo de varios contratos.

Ilan 2002, 216-217, n. 46.

P. Yadin 12.16. Doering 2012, 68.

Respecto a las buenas relaciones de los nabateos con los hebreos y a las rebeliones nabateas contra Roma, véanse las fuentes citadas por Horbury 2014, 328-339.

78 D.C. Epit. Xiph. 69.12.2. Mor 1985, 200-209.

79 Cotton 1999, 219-231. En este artículo Hannah M. Cotton defiende que dos de los documentos escritos en lengua hebrea de Wadi Murabba'at son de la Primera Guerra Judía (66-70): MUR 29 y MUR 30 (222-223).
} 
parte, que había comenzado a difundirse ya en el siglo IV a.C., hasta el punto de que parte del libro de Daniel fue redactado en griego, no se usó en documentos jurídicos hasta el siglo II d.C. El primer contrato en griego de Judea constatado es el matrimonio de Estatilio Máximo Severo Hadriano, datado entre el 100 y el $115{ }^{80}$ Hacia el 132 comenzaron a generalizarse los contratos en griego, incluso cuando las dos partes eran judías. Probablemente este nuevo fenómeno provocó la reacción de Ben Kosiba, que siguió en esta cuestión la línea iniciada por el rabino Josué ben Hananías en 117. El arameo, que se hablaba también en la Arabia Nabatea y en Siria, se escribía de distinta forma en cada región, utilizándose en Judea la misma escritura hebrea cuadrada que se usaba para la lengua hebrea. Los documentos privados de Judea nos muestran un porcentaje mayoritario de textos en arameo con escritura hebrea y un porcentaje minoritario de textos en griego. La lengua hebrea apenas se usaba para documentos privados. Sin embargo, los textos sagrados se leían sólo en hebreo o en griego y se rechazaba su traducción y lectura en arameo.

La política lingüística de Ben Kosiba, que trataba de imponer el uso de la lengua hebrea en la correspondencia de su administración, iba por tanto en contra de la tendencia de su época, pero se parece poderosamente a la política aticista de Adriano: recuperemos nuestra lengua clásica para los documentos escritos. No se trataba simplemente de imitar las tácticas del enemigo para combatirlo, se trataba fundamentalmente de luchar contra la política adrianea de creación de una identidad grecorromana cosmopolita, reivindicando la pureza de la identidad judía. Es precisamente en momentos en que el uso de la lengua se siente como un elemento político contrario a la identidad local cuando se reivindica el uso de lenguas en desuso. Hay muchos ejemplos comparativos que podrían usarse, pero baste el del propio hebreo moderno, nacido como reacción a la expansión del antisemitismo a finales del siglo XIX. Como dice Cotton, no es una coincidencia que en las dos grandes rebeliones judías contra Roma se reutilizara el hebreo en ámbito público y privado y, en consecuencia, es un hecho que "advertises the ideology of the now independent Jewish state. The same ideology stands behind the appearance of Hebrew legends on coins of the two revolts written in the already then obsolete paleo-Hebrew script. Hebrew became the symbol of Jewish nationalism, of the independent Jewish State". ${ }^{81}$

Volviendo a la carta, si admitimos que el autor era nabateo, debemos tener en cuenta qué lengua y escritura utilizaban en esta época los nabateos. De los 38 documentos hallados en el Desierto de Judea que proceden de la vecina provincia de Arabia y están datados entre 106 -fecha de creación de la provincia- y 132, sólo dos están escritos en nabateo, cuatro en arameo con caracteres hebreos y el resto en griego. Esto explicaría que entre los miembros del cortejo de Soumaios no hubiera nadie capaz de escribir en escritura hebrea y sí en griego. Dado que el griego era la escritura y la lengua de las relaciones internacionales podríamos leer la carta en un sentido completamente inverso a su lectura literal: Soumaios no se estaba disculpando, sino que estaba insinuando a los jefes de En Guedi que no le mandasen cartas escritas en hebreo, porque no tenía a nadie que pudiera leerlas, o dicho de otro modo: la política contra la lengua griega de Ben Kosiba no era válida para la obtención de alia-

80 Cotton 1999, 229. En el documento aparece como militar de la Legión X Fretensis y en 115 sería cónsul sufecto, por lo que debió ejercer su cargo en la X Fretensis bastante antes. El cognomen Hadrianus lo adquiriría más tarde.

81 Cotton 1999, 225. 
dos internacionales. Independientemente de que se acepte o no dicha lectura inversa, lo cierto es que el hecho de que Soumaios tuviera que disculparse demuestra la importancia concedida a la política lingüística por parte de los líderes rebeldes.

En este sentido, cabe señalar a Simón ben Kosiba como un "apóstata del helenismo", parafraseando un texto de Elio Arístides titulado "A Platón, en defensa de los cuatro":

Pues engañan como aduladores, son insolentes como los poderosos, son reos de los defectos más extremos y contrarios, la abyección y la arrogancia, semejantes en sus maneras a los impíos que viven en Palestina. Porque la prueba de la impiedad de esa gente es que no creen en los poderes supremos. Y estos hombres, de

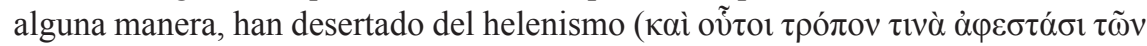
E $\mathrm{\lambda} \lambda \hat{n}(\omega v){ }^{82}$

Como ha advertido Cortés, si no está clara la identificación de los rivales filosóficos de Arístides (probablemente cínicos), es bastante obvio que los "impíos de Palestina que han apostatado de lo helénico" son los seguidores de Bar Kosiba. Y no se puede perder de vista que apostatar de lo helénico ${ }^{83}$ en época de Adriano, era mostrarse claramente en contra de la política imperial.

En cuanto a la Carta de Simón ben Kosiba, no sólo es importante por la aparición de su nombre y su firma autógrafa, como ya se ha comentado al principio, sino también por la cuestión de los galileos. El líder de la rebelión advertía a Josué ben Galgula que aquel que dañase a los galileos que estaban junto a ellos sería encarcelado. Ben Galgula, según Yadin, comandaba el sector norte de la zona dominada por Ben Kosiba en el Desierto de Judá, es decir, la región que va desde Wadi Murabba'at hasta Jericó, aunque se ignora cuál era la sede de su campamento militar.$^{84}$ Dos dudas se plantean: en primer lugar, ¿por qué Simón se ve obligado a proteger a estos galileos de sus propios soldados?, en segundo lugar, ¿a quiénes se refiere como galileos, a simples habitantes de Galilea o a miembros de una secta conocida como "galileos"?

Milik planteó la hipótesis de que se trataba de judeocristianos, basándose en la interpretación que otros investigadores habían hecho previamente del término "galileo" como sinónimo de rebelde, mesiánico o judeocristiano, que tenía su origen en la mención de los galileos por parte de Epicteto como apocalípticos que buscaban el martirio ${ }^{85}$ y en el hecho de que Josefo dijese en su Vida que los galileos habían atacado Tiberíades y, puesto que esta era la capital de Galilea, no estaba usando el término en un sentido geográfico, sino sectario ${ }^{86}$ Yeivin lo interpretó como gentilicio,

82 Aristid. 3.671 L-B, traducción de Cortés 2015, 10-30; este autor defiende la identificación de los "impíos de Palestina" con los seguidores de Bar Kosiba, dado que el texto fue escrito poco más de veinticinco años después de la rebelión (Cortés 2015, 28). Véase también Gascó 1996, 195-202.

${ }^{83}$ Ni griegos ni romanos usaron 'E $\lambda \lambda \eta v i \sigma \mu o ́ \varsigma$ para definir la civilización griega, sino ‘ $2 \lambda \lambda \eta ́ v \omega \nu$ o $E \lambda \lambda \alpha \alpha_{\varsigma}$. El término 'E $\lambda \lambda \eta v \imath \sigma \mu o ́ s$, en fuentes griegas antiguas, significaba “uso de una lengua y un estilo griego puro" (Diog. Bab. Stoic. 3.214; Phld.Po. 2.18; A.D.Pron. 71.25; S.E.M. 1.98; Lex.Vind. 311; Ath. 0.357a; Poxy. 1012 Fr 17).

84 Mor 2016, 455-456. Conocemos a otro hijo de Galgula, Johanán, por el contrato matrimonial de su hija Salomé con Elaios ben Simón, de una aldea de Samaría, ¡escrito en griego!

85 Arr. Epict. 4.7.6.

86 I. Vit. 381. Milik 1953, 276-294; Klausner 1951, 173; Lieberman 1951, 395-404; Gelzer 1952, 67-90. Después de Milik, Martin Hengel argumentó contra la identificación del término con "judeocristiano", pero admitiendo que fuese sinónimo de "revolucionario": Hengel 1961, 57-61; Zeitlin 1973-1974, 189-203. 
considerando que se trataba de rebeldes galileos. ${ }^{87}$ Sin embargo, Bar Kosiba no llegó a dominar nunca Galilea, ${ }^{88}$ con lo que resulta extraña la mención del término en un sentido geográfico, aparte de que el contexto de la carta no invita a pensar en esos galileos como rebeldes antirromanos, sino como enemigos de Bar Kosiba. Feldman rebatió el uso del término en sentido sectario por parte de Josefo, aunque sin entrar a discutir esta carta en su artículo ${ }^{89}$ Sar-Avi, Mor y Martone se inclinan por el sentido gentilicio. ${ }^{90}$ Feyne recientemente ha defendido que Josefo usó el término en sentido sectario sólo en la Vida y no en sus obras anteriores, posibilidad que hay que relacionar con la datación de la Vida en torno al año 100, es decir, poco antes de Epicteto, por lo que es muy posible que dicho uso en este sentido fuese propio de aquella época. ${ }^{91}$

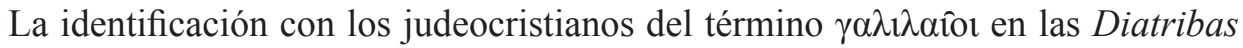
de Epicteto, escritas en 110-115, ${ }^{92}$ tiene además como firme base el hecho de que el filósofo se refiriese a un tipo de judíos propensos al martirio, y los fariseos -desde Gamaliel II (que había pactado con los romanos), pasando por Johanán ben Torta (que rechazó el mesianismo de Bar Kosiba frente a Áquiba) hasta Yehudá Ha Nasí (a quien cabe atribuir que se recogiese por escrito en la literatura talmúdica el nombre de Bar Kozba o "Hijo de la Mentira")- consideraban que era una blasfemia que se intentase propiciar la llegada del Mesías mediante las armas o el martirio, ya que era un asunto que había que dejar en manos de Dios. El hecho de que Epicteto emplease el término "galileo" denota, al menos, que se había difundido el uso del gentilicio como sinónimo de sectario mesiánico. Frente a la moderación de los fariseos de la escuela de Yamnia dirigida por Gamaliel II, su contemporáneo Ignacio de Antioquía era un claro ejemplo de fanatismo por el martirio, como prueba su Carta a los romanos, en la que pedía a sus correligionarios de la capital que no intercediesen por él ante la corte imperial para librarlo de su condena: "El fuego y la cruz, las manadas de fieras, los cortes, las desgarraduras, los quebrantamientos de huesos, los descoyuntamientos de miembros, las trituraciones de todo el cuerpo, los tormentos atroces del diablo, ¡venga todo sobre mí a condición sólo de que yo alcance a Jesucristo!". ${ }^{93}$

Pero hay otro argumento más a favor de la relación entre el término "galileos" y los seguidores de Jesús el Galileo, en el que no se ha reparado suficientemente: el hecho de que el sustantivo abstracto "cristianismo" no aparece en ningún texto anterior al propio Ignacio de Antioquía. Por otra parte, el adjetivo sustantivado "cristiano" no fue usado ni conocido por la inmensa mayoría de los autores neotestamentarios y ni siquiera por los Padres Apostólicos anteriores a Ignacio. ${ }^{94}$ Curiosamente,

87 Yeivin 1955, 108.

88 Según Eck 1999, 87-88, el arco de triunfo construido en Tel Shalem, a 12 km de Escitópolis, indicaría que hubo una batalla importante en Galilea; pero en realidad Escitópolis se situaba en la Decápolis y era una ciudad bastante prorromana, por lo que la situación allí del arco de triunfo pudo tener un sentido más bien propagandístico del apoyo de la ciudad a Adriano durante la guerra. Sobre la extensión geográfica de la rebelión véase Mor 2016, 46-288.

89 Feldman 1981, 50-52.

90 Martone 2012, 41-42; Mor 2016, 172 y 552.

$91 \quad$ Freyne 1980, 398.

92 La fecha de composición de la obra se deduce de la biografía de Flavio Arriano de Nicomedia, senador y amigo de Adriano y uno de los grandes escritores de la época, que estuvo en la escuela de Epicteto en torno a esa fecha tomando apuntes que más tarde publicaría con el título de Diatribas de Epicteto.

93 Ign. Rom 5.3; traducción de Ruiz 1993, 478.

94 Ruiz 1993, 403, n. 21. 
los Hechos de los Apóstoles nos dicen que el término "cristiano" empezó a usarse en Antioquía, ${ }^{95}$ y esta obra probablemente es posterior a las Cartas de Ignacio, como han demostrado múltiples estudios, entre los que voy a reseñar brevemente tan sólo los de Shellard y Nasrallah, el primero porque demostró de forma irrefutable que el autor de Hechos copia - a veces mal- a Flavio Josefo y debe, en consecuencia, datarse posteriormente a la publicación y difusión de sus obras, y el segundo porque ha planteado una interesante hipótesis que señala como motivación y objetivo de la obra la construcción de un cristianismo cosmopolita adaptado al helenismo y al Imperio Romano en el que Pablo actuaría de forma similar a Adriano, viajando por las ciudades griegas para constituir una especie de liga de comunidades cristianas similar a la liga panhelénica creada por el emperador. ${ }^{96}$ Por tanto, puesto que hay indicios claros de que es posterior a Ignacio, habría que plantearse si fue redactado tras conocer las Cartas de Ignacio -y su concepto de cristianismopara explicar cómo pasó el "carisma" de Jerusalén a Antioquía y de Antioquía a Roma. ${ }^{97}$

La fecha del martirio -y de las Cartas - no está del todo clara: según una versión, sería el día 13 antes de las calendas de enero del año del consulado de Sura y Seneción, noveno del imperio de Trajano, es decir, el 20 de diciembre del 107:98 según otra, el 13 de diciembre del 114. ${ }^{99}$ En ambos casos, Adriano debió vivir el proceso de cerca, en el 107 porque era pretor ¡y fue él quien financió los juegos de aquel año! ${ }^{100}$ y en el 114 porque acompañaba a Trajano en la guerra y sería nombrado gobernador de Siria ese año o el siguiente. ${ }^{101}$

95 Hch 11.26.

96 Shellard 2002, 31-34; Nashrallah 2008, 533-566. La tesis de la datación de Hechos en el siglo II fue defendida ya en el siglo XIX por Baur y reivindicada hace medio siglo por O’Neill 1961, 1-63. Actualmente la respaldan la mayoría de los expertos, como Mount 2002; Penner 2004; Pervo 2006; Tyson 2006; Mathhews 2010; Dupertuis - Penner 2014.

97 Los paralelos entre la Carta de Ignacio a los Esmirnotas 1.2 (con Lc 23.6-12 y Hch 4.25-27) y 3,2 (con Lc 24.3643) podrían interpretarse en clave inversa, como influencias de Ignacio en el autor de Lucas-Hechos, ya que parece obvio que Ignacio no conoció la obra lucana. Gregory 2003, 69-75, y 283. Para el paso del carisma de Jerusalén a Antioquía, véase también Rius Camps 1989.

98 Martirium 2.1; Eusebio y Jerónimo. En tal caso, el gobernador de Siria lo habría enviado a Roma para que fuese ejecutado ante las fieras como tantos otros criminales de todo el Imperio, aprovechando la celebración de juegos gladiatorios por parte de Trajano por su victoria en Dacia.

99 Martirium 7.1 dice, sin embargo, que Trajano lo condenó en Antioquía durante la guerra contra los partos. Malalas 11.10-15 da la fecha del 13 de diciembre de 114, dice de Ignacio "que incurrió en la ira del emperador por haberlo insultado", añade que como castigo se produjo un terremoto en Antioquía (también mencionado por Dión: D.C. Epit. Xiph. 68.24.1-25) y sitúa a Adriano en Antioquía durante el martirio de Ignacio: "se hallaba con el emperador Trajano por estar emparentado con él por matrimonio cuando la gran ciudad de Antioquía sufrió la cólera de Dios. Por aquellas fechas era senador" (había ejercido el consulado en 108). Birley 2010, 270-278.

100 H.A. Hadr. 3 detalla su cursus honorum: cuestor en 101, miembro del círculo de confianza de Trajano en la Primera Guerra Dácica (101-102), tribuno de la plebe en 105, legado de la Legión I Minervia durante la Segunda Guerra Dácica (105-106), "alcanzando gran gloria por sus notables hazañas. Por este motivo Trajano le regaló el diamante que había recibido de Nerva, lo que lo elevó a candidato para sucederle. Hecho pretor durante el segundo consulado de Sura y Serviano, recibió de Trajano veinte millones de sestercios para que celebrase juegos". Hay un error: el autor de la Historia Augusta confunde el consulado de Sura y Serviano (102) con el de Sura y Seneción (107), ya que Adriano no pudo ser pretor al año siguiente de ser cuestor ni antes de ejercer como tribuno de la plebe.

101 D.C. Epit. Xiph. 68.17.2-3; Malalas 11.3-4. Trajano partió de Roma a finales de octubre del 113, descansó en Atenas, donde se encontraba Adriano, y ambos llegaron a Antioquía en enero de 114 y regresaron allí a finales de año, tras la conquista de Armenia y norte de Mesopotamia. Sería entonces, el 13 de diciembre, según Malalas, cuando se produciría el martirio de Ignacio. 
Parafraseando a Boyarin, que dijo que Justino Mártir inventó el judaísmo, ${ }^{102}$ yo diría que Ignacio de Antioquía supuso la consolidación del concepto de cristianismo, no sólo porque fue el primero en usar el sustantivo abstracto terminado en "-ismo" para diferenciar su religión de la judía, sino también porque separó el cristianismo del judaísmo, porque usó por primera vez los términos "herejía" y "heterodoxia" para calificar a corrientes como el judeocristianismo y el docetismo, y porque en sus cartas estableció el modelo de Iglesia jerárquica monoepiscopal asistida por presbíteros y diáconos (frente a la estructura primitiva más anárquica que conocemos por la Didajé, con profetas y maestros). ${ }^{103}$

Hasta Adriano, el cristianismo era para los romanos una superstitio judía, como la definieron en 111 Plinio, en 115-116 Tácito y en 121 Suetonio. ${ }^{104}$ En todos estos casos, el término "cristiano" aparece como un calificativo de un grupo humano para distinguirlo de otros. Ninguno de ellos lo usaba para distinguirlo de los paganos, porque no existía una palabra con ese significado en su vocabulario, por lo que lo utilizarían para distinguirlo de otros grupos de judíos. En los textos neotestamentarios este calificativo aparece sólo tres veces: dos en Hechos y una en la Primera Carta de Pedro, escrita en torno al 111. ${ }^{105} \mathrm{Ni}$ Pablo, que se define a sí mismo como judío en Rom 11,1 (porque para Pablo no hay contradicción entre judaísmo y cristianismo, concepto este último que ni siquiera imagina, sólo hay una religión judía renovada por Cristo y practicada por judíos y gentiles temerosos de Dios), ni el Apocalipsis, ni ninguno de los cuatro evangelistas conocían la palabra "cristiano"; pero no sólo eso, sino que tampoco la conoció ni la usó Clemente de Roma en su Primera Carta a los Corintios, datada en torno al año 96. Mucho menos se utilizó el término "cristianismo" ni ningún otro parecido que definiese a la religión cristiana fuera del judaísmo. Porque evidentemente, no tenía entidad propia, diferente del judaísmo. El cristianismo era sólo un tipo de judaísmo más, aunque sus fieles se considerasen a sí mismos como el "resto" elegido de Isaías, compuesto por judíos y gentiles convertidos.

Sólo después de la política religiosa adrianea, que diferenciaría cristianismo de judaísmo, los romanos concebirían el cristianismo como un fenómeno plenamente independiente ya del judaísmo. Y sólo después de Ignacio de Antioquía se aprecia una clara distinción en los escritores cristianos entre su religión y la judía.

102 Boyarin 2001, 427-461, y 2004a, 21-57.

103 Tema que desarrollo en otro artículo (Giménez de Aragón Sierra e.p.).

104 Plin. Ep. 10.96; Tac. Ann. 15.44.2-3; Suet. Claud. 25; Suet. Ner. 16. Para la datación de la Carta de Plinio sigo a Walsh 2006 (el año 112 según Mommsen y el 110 según Sherwin-White 1966).

105 Hch 11.26 y 26.28. 1Pe 4.16. La carta está escrita por la iglesia de Roma, con el pseudónimo de Pedro, “a los que viven como extranjeros en la Dispersión: en el Ponto, Galacia, Capadocia, Asia y Bitinia” (1Pe 1.1). La datación de la carta en la persecución de Plinio en Bitinia se debe a Beare 1947. Posteriormente, exégetas católicos y protestantes han argumentado contra la datación tardía basándose en que la carta no refleja ninguna persecución real y han tratado de datarla entre el 70 y el 95, admitiendo que es posterior a la destrucción de Jerusalén, motivo por el que se define a Roma como Babilonia (1Pe 5.13). En este sentido, Cothenet 1984, 11. Para mí, sus argumentos no son convincentes y el ambiente de persecución es indiscutible: "no os extrañéis por la prueba de fuego que se acerca para examinaros, como si os estuviese sucediendo algo sorprendentemente extraño. Antes bien, en la medida en que participáis de los sufrimientos de Cristo, alegraos ahora, para que podáis alegraros con alborozo cuando se revele su gloria. Si os ultrajan a causa del nombre de Cristo, cuán honorables sois, porque el Espíritu divino de la gloria mora entre vosotros. Que ninguno de vosotros sufra por ser un criminal, o un ladrón, o un malhechor o un delator. No obstante, si sufre por ser cristiano, que no se avergüence sino que glorifique a Dios por llevar ese nombre" (1Pe 4.12-16). Para la investigación sobre 1Pedro anterior a los años 90, Cothenet 1988, 3685-3712. Para las últimas décadas de investigación, Jobes 2005, 5-19; Elliot $2013,9-34$. 
El uso de los sustantivos abstractos "helenismo", "judaísmo" y "cristianismo", para definir civilizaciones, proviene del mundo judío helenizado. Fue en 2 Macabeos donde el término "helenismo" apareció con un sentido que excedía el ámbito lingüístico, en contraposición al término "judaísmo". ${ }^{106}$ Steve Mason ha explicado perfectamente el proceso filológico de creación del neologismo "ioudaïsmós", así como el nuevo matiz que el autor de 2 Macabeos dio al término "helenismós". ${ }^{107}$ Sólo en la Tardoantigüedad comenzaron los paganos a usar el término "helenismo" en un sentido religioso, frente al cristianismo y el judaísmo, como en el caso de Juliano el Apóstata (el mismo, por cierto, que calificaba a los cristianos de "galileos"), uso que recogería el Código de Justiniano. ${ }^{108}$ Hasta entonces, los griegos usaban el término geográfico "Hélade" o el adjetivo "helénico" para definir su civilización, del mismo modo que los romanos utilizaban sólo "Roma" para definir la suya (sería un cristiano, Tertuliano, el que inventaría en latín un sustantivo abstracto para "civilización romana" en contraposición a "civilización cristiana", pero en lugar de elegir el sufijo griego "-ismos", seleccionó el propio del latín para entidades abstractas, "-as": romanitas y christianitas, en español "romanidad" y "cristiandad"). ${ }^{109} \mathrm{Ni}$ siquiera en los textos rabínicos antiguos se usa la palabra judaísmo. Al igual que griegos y romanos, los judíos se referían a su civilización con el término geográfico, Israel. No sería hasta la Edad Media que se acuñase en hebreo el término יהדות, yahadut, para definir la religión judía. No debe extrañar que sean dos autores cristianos -Pablo e Ignaciolos que continúen usando la palabra "judaísmo", puesto que 2 Macabeos, a pesar de su contenido nacionalista y su probable origen fariseo, fue una lectura cristiana más que judía, y sólo se ha integrado en el canon cristiano y no en el judío.

Lo importante de Ignacio en época adrianea no es que el emperador tuvo que conocerlo directamente en el juicio que lo condenó -tanto si fue ejecutado en el 107 como si lo fue en el 114-, lo realmente trascendente es la difusión de copias de sus cartas entre las comunidades cristianas a principios del imperio de Adriano y, con ellas, la expansión del concepto de "cristianismo". En las cartas de Ignacio a las comunidades de la provincia de Asia se planteaba, entre otras cosas, la necesidad de distinguir al cristianismo del judaísmo, así como el conflicto entre la iglesia católica representada por Ignacio y la comunidad judeocristiana.

El conflicto entre cristianos y judíos en Asia Menor ya se apreciaba en dos cartas del Apocalipsis, una a la Iglesia de Esmirna: "Yo conozco tus obras, y tu tribulación, y tu pobreza (pero tú eres rico), y la blasfemia de los que se dicen ser judíos, y no lo son, mas son sinagoga de Satanás"; 110 y otra a la iglesia de Filadelfia, la ciudad fundada por Eumenes II de Pérgamo en honor de su hermano Atalo II Filadelfo, a 133 $\mathrm{km}$ al este de Esmirna subiendo por un afluente del río Hermos:

He aquí, yo entrego de la sinagoga de Satanás a los que se dicen ser judíos y no lo son, sino que mienten; he aquí, yo haré que vengan y adoren delante de tus pies, y que reconozcan que yo te he amado (...) Al que venciere, yo lo haré columna en el

$106 \quad 2 \mathrm{M} 4.13$.

107 Mason 2007, 457-512.

108 Iul. Ep. 84a; Cod. Iust. 1.11.9.1. El concepto de "helenismo" como civilización surgida en el Imperio de Alejandro Magno después de su muerte gracias al sincretismo entre los griego y lo oriental fue creado en el siglo XIX por Droyssen 1834 (segunda edición de 1877-1878).

109 Tert. Palio 4.1. Den Boer 1973.

$110 \quad$ Ap 2.9. 
templo de mi Dios, y nunca más saldrá de allí; y escribiré sobre él el nombre de mi Dios, y el nombre de la ciudad de mi Dios, la nueva Jerusalén, la cual desciende del cielo, de mi Dios y mi nombre nuevo. ${ }^{11}$

Lo más probable es que, cuando se habla de los judíos de la sinagoga de Satanás, se refiera a los fariseos de Yamnia, que en torno al 90, por iniciativa del Nasí Gamaliel II, habían ordenado pronunciar tres veces diarias en las sinagogas la Birkat ha Minim o "Bendición contra los herejes", maldiciendo a los nozrim o "nazarenos", es decir, a los judeocristianos, para impedir su participación en las mismas. ${ }^{12}$ Ahora bien, nótese que el autor les niega el título de judíos, valorándolo pues como positivo, y los califica de "sinagoga de Satanás", reservando evidentemente para sí y los suyos, es decir, para los judeocristianos, el verdadero título de "judíos", el Verus Israel. Entre la época en que se redactarían las cartas a las siete iglesias de Asia que abren el Apocalipsis - generalmente datadas en torno al 95- y la época de las cartas de Ignacio, una o dos décadas posteriores dependiendo de cuándo se date el martirio, hay un abismo en cuanto a mentalidad: Ignacio ya no reclama el título de "verdaderos judíos", sino que, por el contrario, define al cristianismo en oposición al judaísmo.

Lo que Ignacio estaba haciendo era aplicar el mismo criterio usado por $2 \mathrm{Maca}$ beos para definir de forma enfrentada dos realidades culturales, de modo que no existiesen posturas intermedias. Judaísmo o helenismo en el primer caso, cristianismo o judaísmo en el caso de Ignacio. Si 2 Macabeos deseaba eliminar las posturas intermedias entre helenistas y hasidíes, defendidas por el Sumo Sacerdote Alcimos, Ignacio deseaba eliminar el judeocristianismo, que se situaba entre el judaísmo y el cristianismo católico.

El conflicto entre los cristianos de origen judío y los de origen gentil en Antioquía se había producido, como es notorio, en época apostólica, entre Pedro y Pablo, recriminando este último al líder de los Doce que desde que habían llegado mensajeros de Santiago el hermano de Jesús ya no comía con los cristianos de origen gentil, tal como narra en Gálatas, donde además dice que Santiago le otorgó a él la misión sobre los gentiles y a Pedro la evangelización de los judíos. Es digno destacar que, según las Constituciones Apostólicas, Ignacio habría sido nombrado obispo por Pablo mientras que Pedro nombró a Evodio. ${ }^{113}$ Un "inspector", pues, para los cristianos gentiles y otro para los judeocristianos. Esta posibilidad es desde luego mayor que la de la existencia de un monoepiscopado en Antioquía, ya que en el siglo I el número de obispos o inspectores de una comunidad dependía de su tamaño y el monoepiscopado sólo se impondría a partir del siglo II, precisamente gracias a la defensa que de él hizo Ignacio, que debió en algún momento (quizás a la muerte de Evodio), lograr la unidad total de su comunidad, sin distinciones entre cristianos de origen judío o gentil, como defendía Pablo. 1Clemente, por ejemplo, escrita por el secretario $a b$ epistulis del consejo de presbíteros de Roma, habla de una iglesia de Corinto gobernada por el consejo de presbíteros: "someteos a los presbíteros", ${ }^{114}$ mientras que los obispos aparecen como cargos secundarios similares a los diáconos. ${ }^{115}$ Del mismo

\footnotetext{
Ap 3.9 y 12.

112 Las tesis de Vana 2001 y Bobichon 2003 contrarias a la inclusión de los nozrim en Yamnia fueron rebatidas por Jaffé 2009, 127-142, y Marcus 2009, 523-551; para el estado de la cuestión, Langer 2012, 16-39.

113 Const. App. 7.46.

114 1Cle 57.1.
}

$115 \quad 1$ Cle 42. 
modo, en 1Pedro se aprecia que las provincias romanas de Anatolia estaban dirigidas por colegios de presbíteros remunerados. ${ }^{116}$ En ambos casos se trata de un paso en la evolución desde las iglesias anteriores a la Didajé, controladas por profetas y maestros. No había monoepiscopado ni en Roma, ni en Corinto, ni en las provincias anatólicas en torno al año 100. De las cartas troyanas de Ignacio se desprende que la unidad y la paz no se lograron en la iglesia de Antioquía hasta su captura y envío a Roma (Filadelfios, Esmirnotas y Policarpo), por lo que es muy posible que hubiera ciertas divisiones entre judeocristianos, católicos y docetas. La unidad era también el objetivo que perseguía con las cartas a las iglesias de la provincia de Asia, entendiéndose por unidad la necesidad de acabar con la pluralidad de pensamiento en las comunidades cristianas. Ignacio pensaba que debía lograrse no sólo combatiendo las ideas de docetas y judeocristianos, sino también favoreciendo la imposición del monoepiscopado, que él había implantado en Antioquía y temía desapareciera. ${ }^{117}$ Quizás cuando dice en las cartas desde Tróade que se alegra de que la paz haya llegado a la iglesia de Siria es porque le ha llegado la noticia del nombramiento de su sucesor, Herón, que había sido diácono suyo y habría conseguido el apoyo unánime de la mayoría de los presbíteros.

Para obligar a los judeocristianos a transigir o abandonar la iglesia, inventó un concepto nuevo, aplicando el sufijo "-ismo" al adjetivo "cristiano", como había hecho el autor de 2 Macabeos dos siglos y medio antes. Esta palabra aparece en tres de sus cartas, Magnesios, Filadelfios y Romanos. ${ }^{118}$ En las dos primeras se usa para definir a su comunidad de creyentes frente al "judaísmo" y en la tercera frente al "mundo", es decir, frente a la sociedad grecorromana. Ignacio de Antioquía, en conclusión, dio el paso fundamental para que el cristianismo dejara de ser considerado una secta judía, porque creó un neologismo que englobaba no sólo a las personas que profesaban la religión de Cristo, sino a la propia religión y el modo de vida con ella relacionado, diferenciándola así del judaísmo que no se concibe sólo como una religión sino, al modo de 2 Macabeos, como una civilización con su sistema político, social, económico, cultural.

La invención reciente del neologismo "cristianismo" en época de Bar Kosiba es, en definitiva, un argumento más a favor del posible uso del término "galileos" en la carta que nos ocupa como sinónimo de sectarios mesiánicos, seguidores de Jesús el Galileo. Pero incluso aunque no se admitiesen estos argumentos a favor de este uso del término en dicha carta, el hecho de que el líder de la rebelión se viese obligado a prohibir a sus hombres que dañaran a los galileos indica que había una gran animadversión hacia ellos entre los rebeldes. De hecho, tuvo que amenazar a los hombres de la fortaleza de Josué ben Galgula con ponerles cepos en los pies, lo cual implica que ya se habían producido excesos de violencia contra prisioneros "galileos". Si aceptamos la lectura de Birnbaum sobre Áquiba, anteriormente mencionada, Bar Kosiba estaba siguiendo la política iniciada por el gran rabino que lo proclamó Mesías. Y si no la aceptamos, el mismo Bar Kosiba habría castigado ya a Ben Aflil u otros por la violencia contra los galileos. En cualquier caso, estos "galileos" se oponían vehementemente al mesianismo del "Hijo de la Estrella" y por ello estaban prisioneros de Ben Galgula. Por tanto, incluso aquellos que se inclinan por el sentido gentilicio del

\footnotetext{
$116 \quad 1$ Pe 5.2.

117 Rom 9.1.

118 Magn 10.1-3, Fil 6.1-9.1 y Rom 3.2.
} 
término tendrían que argumentar a qué corriente del judaísmo de la época pertenecían esos galileos, dada su oposición a los rebeldes.

Mor ha estudiado a fondo la oposición a Bar Kosiba: aparte de los judeocristianos, hubo divisiones entre los fariseos y también hubo fricciones entre los propios comandantes rebeldes, como demuestra el propio tono de la carta, especialmente en los últimos tiempos de la rebelión, cuando el fracaso de la misma comenzaba a hacerse patente. ${ }^{119}$ Los enfrentamientos entre los líderes rebeldes se producirían, entre otros motivos, por el diferente modo de reprimir a la población contraria a la revuelta, y esta parece ser la causa de esta carta: impedir a Josué ben Galgula y a sus hombres que actuasen demasiado duramente contra los galileos de su región, al norte del Mar Muerto, zona antiguamente poblada por esenios, de los que en esta época no quedaba ni rastro.

La noticia clave respecto a la división entre los rabinos es la del Talmud de Jerusalén. Tras citar la profecía del Hijo de la Estrella, ${ }^{120}$ "cuando Rabí Áquiba vio a Bar Kozba, dijo: Este es el Rey, el Mesías. Rabí Johanán bar Torta le dijo: Áquiba, la hierba brotará de tus mejillas y el Hijo de David todavía no habrá venido". ${ }^{21}$ La interpretación tradicional de este pasaje convertía a Áquiba en el líder espiritual de la revuelta y a Johanán bar Torta en el representante de la facción farisea que tomaría el control del judaísmo después de Bar Kosiba. Aunque Mor discuta el hecho de que Áquiba fuera realmente el ideólogo de la revuelta basándose en la debilidad de las pruebas al respecto -así como en una noticia tardía que data la muerte de Áquiba en el 132 en Cesarea, justo antes de que estallase la revuelta ${ }^{122}$ reconoce, en cualquier caso, que Áquiba y Johanán Ben Torta representaban las dos facciones del fariseísmo que discutían sobre el carácter del "Mesías": para Áquiba sería un Mesías político que liberaría a los judíos de la dominación romana mientras que para Ben Torta sería un Mesías espiritual, el Mesías del Fin de los Tiempos, y de linaje davídico. Y no consta que Bar Kosiba se proclamara descendiente de David, más bien parece que era de linaje sacerdotal, ya que su tío Rabí Eleazar Hamodai lo era. ${ }^{123}$

No se sabe gran cosa sobre Johanán ben Torta, ${ }^{124}$ ni siquiera quién fue su maestro. El hecho de que el rival de Áquiba en los debates de la literatura rabínica fuese casi siempre Rabí Eleazar ben Azarías, ${ }^{125}$ de linaje sacerdotal, que detentó el cargo de Nasí durante un corto período en que Gamaliel II fue depuesto, puede interpretarse como indicio de una relación intelectual entre ambos, pero no hay nada seguro. Por otra parte, Eleazar ben Azarías permitió el regreso de Gamaliel II al cargo de Nasí al cabo de un tiempo y quedó como vicepresidente del sanedrín de Yamnia hasta la muerte de Gamaliel, que se suele datar poco antes del 115, ya que no hay noticias de ningún tipo que lo relacionen con la Guerra de Qitos. El cargo de Nasí o Patriarca de los judíos habría comenzado a tener reconocimiento oficial romano a partir de la muerte de Domiciano, y se situaría en el mismo contexto que la abolición del Fiscus

119 Mor 2016, 395-402 (judeocristianos) y 454-467 (fariseos y líderes rebeldes).

$120 \quad \mathrm{Nm} 24.17$.

121 Taanit 4.8; tradición paralela en Midrás Lamentaciones Rabba 2.4.

122 Tratados menores, Semahot 8.9.

123 Talmud de Babilonia Gittin 57a; Midrás de Lamentaciones Rabba 2.5. Sobre la posible identificación de Eleazar Hamodai con el "Eleazar Ha Cohen” de las monedas de la rebelión de Bar Kokhba, véase Mor 2016, 429-439.

124 Una tradición tardía lo hace prosélito: PR, Parah 56b-57a. Sólo hay otro dicho suyo en la literatura rabínica, sobre la causa de la destrucción del Templo: Toseftá Men. 13.22.

125 Son muchas las citas sobre el pensamiento de Eleazar ben Azarías y su discusión con Áquiba en la literatura talmúdica. 
Iudaicus por parte de Nerva, en plena presencia en Roma de Gamaliel II, adonde acudió por orden de Domiciano, quizás para ser juzgado como descendiente de David (como los nietos de Judas, uno de los hermanos de Jesús, que fueron juzgados por aquel entonces según Hegesipo), ${ }^{126}$ o quizás por la necesidad de encontrar un sustituto para el difunto Agripa II como interlocutor oficial con las autoridades romanas. Lo que ocurrió a la muerte de Gamaliel II se ignora. Metzger cree que le sucedió su hijo Hanina ben Gamaliel, del que apenas se sabe nada, ${ }^{127}$ y Alon que lo haría Eleazar ben Azarías, y tras él -que debió fallecer pronto-, Rabbí Tarfón, que murió justo antes de la rebelión de Bar Kosiba. ${ }^{128}$ Mor cree que como consecuencia de la Guerra de Qitos, Adriano no reconocería a ningún líder judío, por lo que el cargo de Nasí quedaría vacante. ${ }^{129}$ Es posible que los rabinos mencionados ejercieran su autoridad de forma colegiada. También hay que contemplar la hipótesis de Peleg mencionada anteriormente, que considera que Adriano nombró Nasí de los judíos a Bar Kosiba en el 117. En cualquier caso, hay que destacar que Rabí Tarfón (cuyo nombre en textos griegos se traduce como Trifón, casualmente el mismo de aquel sabio judío con el que Justino Mártir discutió durante la guerra) ejerció una gran autoridad en los años inmediatamente anteriores a la guerra, que era un rabino de linaje sacerdotal que defendía la escuela de Shammai frente a la de Hilel y que su actitud hacia los judeocristianos fue especialmente dura y juró quemar los libros de los cristianos aunque en ellos estuviese escrito el nombre de Dios (Shab. 116a).

Después de Adriano, sin embargo, el cargo de Nasí o Patriarca de los judíos volvió a la dinastía davídica de Hilel (bien en la figura de Simón ben Gamaliel II, bien en la de su hijo Yehudá Ha Nasí, Rabbi, redactor de la Misná), que lo monopolizaría hasta el 30 de mayo del año 429 cuando Teodosio II, tras la muerte sin herederos de Gamaliel VI, suprimió por decreto dicho patriarcado. ${ }^{130}$ Puesto que Simón ben Gamaliel II era un joven durante la guerra, que permaneció en la fortaleza de Betar hasta poco antes de su destrucción por Adriano, y dado que no tuvo a su primogénito, Yehudá Ha Nasí, hasta el día de la ejecución de Áquiba, lo lógico es suponer que la oposición a Bar Kosiba en el seno del fariseísmo la liderasen otros, como el ya mencionado Ben Torta. No sabemos si el hecho de que Simón ben Gamaliel estuviese en Betar significa que apoyó totalmente a Bar Kosiba (que había arrebatado el título de Nasí a su familia), pero lo cierto es que su hijo y redactor de la Misná compartiría la visión negativa sobre Bar Kozbah, el "Hijo de la Mentira". Sin embargo, Yehudá Ha Nasí fue discípulo de Rabbí Meir, que a su vez lo fue de Rabbí Áquiba. Quizás tenga razón Mor y el apoyo de Áquiba a Bar Kosiba fue relativo, y el debate con Ben Torta sólo es una muestra de las típicas disertaciones intelectuales rabínicas, en este caso sobre la naturaleza del Mesías. ${ }^{131}$ Pero en cualquier caso, está claro que los discípulos de Áquiba y el propio Simón ben Gamaliel no formaron parte de la oposición a Bar Kosiba y sólo después de su fracaso lo despreciaron como un falso Mesías.

En consecuencia, es más probable que los galileos mencionados en la carta, independientemente de que el término fuese usado en sentido geográfico o en sentido sectario (aspecto imposible de resolver definitivamente con las fuentes actualmente

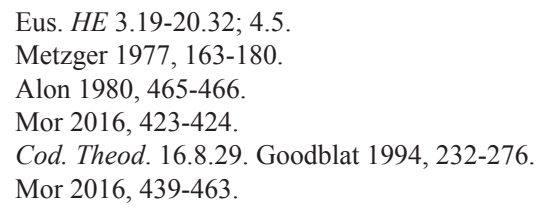


disponibles), perteneciesen a la iglesia judeocristiana, que ya tenía su propio Mesías, en cuyo nacimiento se cumplió la profecía de la estrella, cuestión muy viva en aquel tiempo como nos demuestra de nuevo Ignacio de Antioquía:

Y quedó oculta al Príncipe de este mundo la virginidad de María y el parto de ella, del mismo modo que la muerte del Señor: tres misterios sonoros que se cumplieron en el silencio de Dios. Ahora bien, ¿cómo fueron manifestados a los siglos? Brilló en el cielo un astro más resplandeciente que los otros astros. Su luz era inexplicable y su novedad produjo extrañeza. Y todos los demás astros, juntamente con el sol y la luna, hicieron coro a esta nueva estrella; pero ella, con su luz, los sobrepujaba a todos. Sorprendiéronse las gentes, preguntándose de donde pudiera venir aquella novedad tan distinta de las demás estrellas. ${ }^{132}$

Hay que tener en cuenta, además, que Galilea no era aún territorio adoctrinado por los rabinos fariseos, cuya sede estaba en Yamnia y cuya zona de predicación era fundamentalmente Judea. Sería después de la guerra de Bar Kosiba cuando los judíos fuesen expulsados de Judea y Simón ben Gamaliel II trasladase la sede del sanedrín o tribunal rabínico a Usha, en Galilea, donde se redactaría la Misná. Su nieto Gamaliel III la trasladaría a Tiberíades. En definitiva, a partir de mediados del siglo II, Galilea sería la región en la que predominaría el judaísmo, mientras que en Judea se desarrollaban, desde el reinado de Adriano, dos de las principales sedes del cristianismo, Jerusalén y Cesarea, pero de cristianismo exclusivamente gentil. Por ello, el término "galileo" como sinónimo de judeocristiano dejó de tener sentido tras la guerra y fue totalmente sustituido por el término usado por los antioquenos: "cristiano". Pero en época de Epicteto, Adriano y Bar Kosiba todavía no era así.

En cuanto a la política de los rebeldes hacia los cristianos, Justino Mártir dijo que Bar Kokhba ordenó torturar a los cristianos hasta que renegasen de Cristo y lo admitiesen a él como verdadero Mesías, y en términos similares se manifestaron escritores posteriores como Eusebio, Jerónimo y Orosio. ${ }^{133}$ Sin embargo, la Carta de Ben Kosiba nos lo muestra frenando los excesos de sus lugartenientes. Este importante documento histórico confirma, por una parte, el hecho de que hubo represión de aquellos judíos que no aceptasen el mesianismo del "Hijo de la Estrella", pero matiza, por otra parte, el papel del líder de la rebelión, más moderador que incitador de la represión. El hecho de que Ben Kosiba protegiese de la tortura a estos "galileos" tiene su explicación lógica: el líder de la revuelta tenía la esperanza de que tras la victoria los mesiánicos galileos lo reconocieran como Mesías verdadero. ${ }^{134}$ Este hecho histórico indiscutible -el de la protección de los galileos del Desierto de Judá por parte de Bar Kosiba-, nos sitúa mejor que ninguna fuente eclesiástica posterior en el

132 Ign. Efes 19.1-2.

133 Iust. Phil. 1Apol. 31.6; Eus. HE 4.8.4, Hieron. Chron. 201; Oros. Hist. 7.13.4.

134 Recientemente Menahem Mor (2016, 403-429) ha intentado desconectar el movimiento de Bar Kosiba del mesianismo, pero sus argumentos no me resultan convincentes. Por una parte, se basa en el hecho de que en las cartas no aparece como "Mesías" sino como "Nasí" y, por otra, intenta desvincular el título de "Nasí" del mesianismo, para lo que se ve obligado a negar la historicidad de la mayor parte de las fuentes al respecto. Pero el carácter mesiánico del título de "Nasí" aparece en Ez 44-66 y conectado con la dinastía davídica en Ez 34.24; y por otra parte no es incompatible que usase distintos títulos. Si la noticia cristiana (Eus. HE 4.6) se encontrase aislada, podría considerarse una interpretación sesgada de los cristianos, pero no ya con el apoyo de las monedas en que aparece una estrella y la ya mencionada noticia del Talmud de Jerusalén Ta'aniot 4.68d. 
pensamiento mesiánico de la época, que aún relacionaba las profecías del Antiguo Testamento con la liberación política de Israel respecto a los imperios paganos.

Respecto a los judeocristianos, hay que tener en cuenta, además, que en Judea y Galilea ya había por aquel entonces una importante población cristiana de origen gentil, como nos indican los Hechos de los Apóstoles al referirse a la predicación de los helenistas y de Pedro en Cesarea y la costa palestina y como nos prueba el propio Justino Mártir, cristiano gentil nacido en Cesarea. Los judeocristianos se vieron obligados durante la rebelión a elegir entre apoyar a sus compatriotas judíos o a sus correligionarios gentiles. Y sin duda muchos optaron por sus hermanos de fe, de ahí que fueran perseguidos y maltratados por los hombres de Bar Kosiba.

Es posible que esta persecución de los cristianos por parte de los rebeldes hiciese inclinar la simpatía de Adriano hacia los creyentes en el Mesías galileo, como también pudo hacerlo el paralelismo de esta religión y la suya propia, en la que un ser humano se podía convertir en dios (Antinoo, su mujer, él mismo), o incluso su carácter mistérico con un culto a un dios que muere y resucita similar al de los misterios eleusinos o a la figura de Dionisios, con el que también se identificó. Lo más probable, en mi opinión, es que estas cosas influyeran menos que el carácter más asimilable del cristianismo con respecto al judaísmo. Los cristianos estaban más helenizados y eran romanizables. Hasta Adriano, los romanos no habían distinguido el cristianismo del judaísmo. El cristianismo era una corriente religiosa más dentro del judaísmo del siglo I, como el esenismo, el fariseísmo, el saduceísmo o el bautismo, que se consideraba a sí misma el Verus Israel, al igual que los sectarios de las otras corrientes. Adriano y algunos intelectuales cristianos de origen gentil fueron los responsables de la separación radical entre judaísmo y cristianismo. Se produjo en aquel momento una coincidencia entre los intereses e ideas de estos intelectuales cristianos y los intereses e ideas del emperador, similar a la coincidencia señalada por Galimberti en relación a los deseos de los ciudadanos griegos y la política adrianea: "siamo di fronte ad uno di quei casi in cui istanze "dal basso" e istanze "dall'alto" si integrano felicemente". ${ }^{135}$ En la misma línea de Ignacio de Antioquía se pronunciarían el autor de 1Pedro, Arístides de Atenas el Apologeta y Bernabé. Fruto de las apologías de Arístides y Quadrato en el 124 sería la derogación de la legislación trajanea respecto a la persecución de los cristianos que se aprecia en las Cartas de Plinio, si aceptamos como histórica la Carta de Adriano a Minucio Fundano. ${ }^{136}$

E indiscutible es que, tras la derrota de Bar Kosiba, el emperador Adriano prohibió la presencia de judíos circuncidados en Jerusalén y su región, la pequeña Judea, pero no la presencia de cristianos. Frente a la política antihelenística de Bar Kosiba, Adriano tomó medidas contundentes y muy diferentes para judíos circuncidados que para samaritanos y cristianos. Los rabinos de tendencia farisea trasladaron sus escuelas a Galilea, mientras al sur, en las regiones dominadas por Jerusalén y Cesarea, proliferaban los cristianos gentiles y aquellos judeocristianos que abandonaron la circuncisión. Sería un error histórico considerar que Adriano no era consciente de lo que hacía diferenciando entre judíos y cristianos. No podemos ignorar el conocimiento que el emperador tuvo a lo largo de su vida del hecho judío y del hecho cris-

135 Galimberti 2016, 135.

136 Eus. HE 4.9. Ni Trajano ni Adriano aceptaban las delaciones anónimas, pero Trajano aceptaba que se condenase a todo aquel cristiano que no abjurase de su religión, mientras que Adriano sólo a aquellos que se probase que hubiesen cometido un delito, proponiendo también castigos para los denunciantes falsos. 
tiano. Tuvo noticias de ellos a través de la experiencia de su pariente Trajano el Viejo, legado de la X Legión durante la destrucción de Jerusalén en el 70, gobernador de la Bética en el 72 (donde vendería centenares de esclavos judíos obtenidos en la guerra), gobernador de Siria en el 74, tras la rendición de Masadá y el traslado a Jerusalén de la X Legión. Quizás incluso tuvo contacto con ellos, dados los juicios de Domiciano contra los senadores que profesaban el cristianismo (o el judaísmo o, más probablemente, el judeocristianismo), como es el caso de Flavio Clemente, miembro de la familia imperial, y Acilio Glabrión, colega de Trajano en el consulado a cuyo hijo nombró Adriano como senador, restaurando el honor de la familia. Participó en el martirio de Ignacio de Antioquía. Conoció la no participación de los cristianos en la Guerra de Qitos y es muy probable que, como gobernante de Siria que era entonces, se reuniera con los líderes judíos y cristianos de Antioquía. Recibió al obispo Quadrato de Atenas y al filósofo cristiano Arístides el Apologeta. Decretó medidas contra las persecuciones de los cristianos como consta por la Carta de Minucio Fundano. Se reunió con sabios samaritanos y con rabinos fariseos. Sus medidas, fruto de un conocimiento bastante profundo del fenómeno, estuvieron guiadas por la misma doctrina política que presidía todos sus actos: la necesidad de crear una identidad romana única, global, cosmopolita, que unificara a todos los pueblos del Imperio. Y si debía elegir entre los fariseos y los cristianos, era obvio que los cristianos eran romanizables. Debió pensar que quizás permitiendo su presencia en Jerusalén y cesando las persecuciones en las provincias el problema judío acabaría disolviéndose, potenciando la transformación de los judíos de Judea y la Diáspora en cristianos, factor que les permitiría a unos la residencia en su ciudad sagrada y a otros su mayor integración en la sociedad romana. Se equivocó. Pero su política religiosa diferenciando a judíos de cristianos tuvo una serie de consecuencias todavía más trascendentes, un efecto que sin duda nunca pudo imaginar: el cristianismo no sólo continuó romanizándose e integrándose en la sociedad imperial, sino que logró judaizar Roma hasta el punto de convertirla en la sede de la secta de Jesús el Galileo.

\section{Referencias bibliográficas}

Acerbi, S. (2003): "Circumcision and Castration under Roman Law in the Early Empire", [en] E. Wyner Mark (ed.), The Covenant of Circumcision. New Perspectives on an Ancient Jewish Rite, Hanover-London, 75-86.

Alon, G. (1980): The Jews in Their Land in the Talmudic Age, 70-640 C.E., Jerusalem.

Alonso, C. - Alarcón, J. J. (2006): "Las cartas arameas de Bar Kokba: texto, traducción y comentario", Sefarad 66, 23-54 (https://doi.org/10.3989/sefarad.2006.v66.i1.423).

Applebaum, S. (1984): “The Second Jewish Revolt (AD 131-135)", Palestine Exploration Quartely 160, 35-41(https://doi.org/10.1179/peq.1984.116.1.35).

Baker, R. (2012): "Epiphanius on Weights and Measures§ 14: Hadrian’s Journey to the East and the Rebuilding of Jerusalem", Zeitschrift für Papyrologie und Epigraphik 182, 157167.

Bazzana, G. (2010): “The Bar Kokhba Revolt and Hadrian’s Religious Policy”, [en] M. Rizzi (ed.), Hadrian and the Christians (=Millenium Studies 30), Berlin.

Beare, F. W. (1947): The First Epistle of Peter. The Greek Text with Introduction and Notes, Oxford.

Belayche, N. N. (2001): Iudaea-Palestina: The Pagan Cults in Roman Palestine (=Religion der Römischen Provinzen 1), Tübingen. 
Benoit, P. - Milik, J. T. - De Vaux, R. (1961): Les Grottes de Murabba' ât (Discoveries in the Judaean Desert II), Oxford.

Birley, A. (2010): Adriano, Madrid.

Birnbaum, S. (1954): "Bar Kokhba and Akiba", Palestine Exploration Quarterly 86, 23-32 (http://dx.doi.org/10.1179/peq.1954.86.1.23).

Bobichon, Ph. (2003): "Persécutions, calomnies, 'Birkat Ha-Minim' et émissaires juifs de propagande antichrétienne dans les écrits de Justin Martyr", Revue des Études Juives 162/3-4, 403-419 (http://dx.doi.org/10.2143/REJ.162.3.503632).

Boyarin, D.

(1994): A Radical Jew: Paul and the Politics of Identity (=Contraversions: Critical Studies in Jewish Literature, Culture, and Society 1), Berkeley.

(2001): “Justin Martyr invents Judaism", Church History 70/3, 427-461 (http://dx.doi. org/10.2307/3654497).

(2004a): "The Christian Invention of Judaism: The Theodosian Empire and the Rabbinic Refusal of Religion", Representations 85, 21-57 (http://dx.doi.org/10.1525/rep.2004. 85.1.21).

(2004b): Border Lines: The Partition of Judaeo-Christianity, Philadelphia. (2012): The Jewish Gospel. The Story of the Jewish Christ, New York.

Bricault, L. (éd.), (2004): Isis en Occident. Actes du Ilème Colloque international sur les études isiaques, Lyon III, 16-17 mai 2002, Leiden.

Capponi, L. (2010): "Hadrian in Jerusalem and Alexandria in 117”, Athenaeum 98/2, 489-501.

Cordier, P. (2001): “Les romains et la circoncision", Revue des Études Juives 160, 337-355.

Cortés, J. M. (2015): "Paideia e Imperio: una reflexión sobre el valor de la cultura como fundamento del dominio imperial”, Anuario de Historia Virtual 8, 10-30.

Cothenet, E.

(1984): Las cartas de Pedro (=Cuadernos bíblicos 47), Estella.

(1988): "La Première de Pierre: bilan de 35 ans de recherches", Aufstieg und Niedergang der römischen Welt 25.5, 3685-3712.

Cotton, H. M. (1999): "The Languages of the Legal and Administrative Documents from the Judaean Desert”, Zeitschrift für Papyrologie und Epigraphik 125, 219-231.

Cusumano, N. (1992): "I culti di Adrano e di Efesto. Religione, politica e acculturazione in Sicilia tra il V e il IV secolo", Kokalos 38, 151-189.

Den Boer, W. et alii (1973): Romanitas et Christianitas. Studia J. H. Waszink oblata, Amsterdam.

Doering, L. (2012): Ancient Jewish Letters and the Beginnings of Christian Epistolography (=Wissenschaftliche Untersuchungen zum Neuen Testament 298), Tübingen.

Droyssen, J. G. (1834): Geschichte des Hellenismus, Berlin.

Dupertuis, R. R. - Penner, T. (eds.), (2014): Engaging Early Christian History. Reading Acts in the Second Century, New York.

Eck, W. (1999): "The bar Kokhba Revolt: The Roman Point of View", Journal of Roman Studies 89, 76-89 (http://dx.doi.org/10.2307/300735).

Eliav, Y. Z. (1997): "Hadrian's Actions in the Jerusalem Temple Mount According to Cassius Dio and Xiphilini Manus", Jewish Studies Quarterly 4/2, 125-144.

Elliot, J. H. (2013): La Primera Carta de Pedro, Salamanca.

Evans, J. R. (2011): "From Mountain to Icon: Mount Gerizim on Roman Provincial Coins from Neapolis, Samaria", Near Eastern Archaeology 74/3, 170-182 (http://dx.doi. org/10.5615/neareastarch.74.3.0170).

Feldman, L. (1981): “The Term 'Galileans' in Josephus”, Jewish Quarterly Review 72/1, 5052 (http://dx.doi.org/10.2307/1454166).

Floristán, J. M. (1994): “Arriano, aticismo y koiné”, Cuadernos de filología clásica 4, 161-187. (1995): “Arriano, aticismo y koiné”, Cuadernos de filología clásica 5, 91-141. 
Freyne, S. (1980): “The Galileans in the Light of Josephus Vita", New Testament Studies 26, 397-413 (http://dx.doi.org/10.1017/S0028688500022414).

Galimberti, A. (2007): Adriano e l'ideologia del principato (=L'Erma di Bretschneider. Monografie del centro ricerche e documentazione sull'antichità classica 38), Roma.

García, L. (1993): "Las revueltas judías en tiempos de Trajano", [en] J. González (ed.), IMP. CAES. NERVA TRAIANUS AUG., Sevilla, 137-149.

Garzón, J. A.

(1989): “Los símbolos numismáticos de 'La Edad de Oro de los Antoninos': Felicitas, Hilaritas y Laetitia”, Studia Historica. Historia Antigua 7, 153-162.

(1993): "Iconografía de las provincias en Trajano, Adriano y Antonino Pío", Faventia 15/2, $75-85$.

Gascó, F. (1996): Opuscula selecta (=Aldina 6), Sevilla-Huelva.

Geiger, Y.

(1976): "The Ban on Circumcision and the Bar-Kokhba Rebellion", Zion 41, 139-147.

(2016): “The Bar-Kokhba Revolt: The Greek Point of View”, Historia 65/4, 497-519.

Gelzer, M. (1952): “Die Vita des Josephos", Hermes 80, 67-90.

Giménez de Aragón, P. (e.p.): "Ignacio de Antioquía inventó el cristianismo. Trajano y Adriano frente a los cristianos", ARYS 16.

Goodblat, D. M. (1994): The Monarchic Principle: Studies in Jewish Self-goverment in Antiquity (=Texte und Studien zum Antiken Judentum 38), Tübingen.

Gordillo, R. (2012): La construcción religiosa de la Hélade Imperial: el Panhelenion (=Università degli Studi di Firenze. Premio tesi di dottorato 27), Firenze.

Graetz, H. (1891): History of the Jews from the Earliest Times to the Present Day, Berlin.

Gregory, A. (2003): The Reception of Luke and Acts in the Perios before Irenaeus: Looking for Luke in the Second Century (=Wissenschaftliche Untersuchungen zum Neuen Testament 2.169), Tübingen.

Hadas-Lebel, M. (2006): Jerusalem against Rome (=Interdisciplinary Studies in Ancient Culture and Religion 7), Leuven-Dudley.

Hengel, M. (1961): Die Zeloten. Untersuchungen zur jüdischen Freiheitsbewegung in der Zeit von Herodes I. bis 70 n. Chr. (=AGJU 1), Leiden-Köln.

Hezser, C. (2018): "Uncertain Symbol: The Representation of Yavne in the Talmud Yemshalmi", [en] J. Schwartz - P. J. Tomson (eds.), Jews and Christians in the First and Second Centuries: The Interbellum 70-132 CE (=Compendia Rerum Iudaicarum ad Novum Testamentum 15), Leiden-Boston, 176-195 (http://dx.doi.org/10.1163/9789004352971).

Horbury, W. (2014): Jewish War under Trajan and Hadrian, Cambridge (https://doi. org/10.1017/CBO9781139049054).

Ilan, T. (2002): Lexicon of Jewish Names y Late Antiquity. Part I. Palestine 330 BCE - 200 $C E$ (=Texts and studies in ancient Judaism 91), Tübingen.

Isaac, B. (2004): "La política religiosa de Adriano y la Segunda Revuelta Judía", [en] J. M. Cortés - E. Muñiz (eds.), Adriano Augusto, Sevilla, 139-151.

Jaffé, D. (2009): El Talmud y los orígenes judíos del cristianismo. Jesús, Pablo y los judeocristianos en la literatura talmúdica, Bilbao.

Jobes, K. H. (2005): 1Peter, Grand Rapids.

Langer, R. (2012): Cursing the Christians? A History of the Birkat HaMinim, Oxford (http:// dx.doi.org/10.1093/acprof:oso/9780199783175.001.0001).

Lapin, H. (1993): "Palm Fronds and Citrons: Notes on Two Letters from Bar Khosiba's Administration", Hebrew Union College Annual 64, 111-135.

Lieberman, S. (1951): "Light on the Cave Scrolls from Rabbinic Sources", Pan American Journal of Aging Research 20, 395-404 (http://dx.doi.org/10.2307/3622176).

Lifshitz, B. (1962): "Papyrus grecs du désert de Juda", Aegyptus 42, 240-258.

Klausner, J. (1951²): History of the Second Temple, Jerusalem. 
Marcus, J. (2009): “Birkat Ha-Minim Revisited”, New Testament Studies 55, 523-551 (https://doi.org/10.1017/S0028688509990063).

Martone, C. (cur.), (2012): Lettere di Bar Kokhba (=Testi del Vicino Oriente antico 6. Letteratura ebraica e aramaica 2$)$, Brescia.

Mason, S. (2007): "Jews, Judeans, Judaizing, Judaism: Problems of Categorization in Ancient History", Journal for the Study of Judaism 38, 457-512 (http://dx.doi. org/10.1163/156851507X193108).

Mathhews, Sh. (2010): Perfect Martyr: The Stoning of Stephen and the Legacy of Paul, Oxford (http://dx.doi.org/10.1093/acprof:oso/9780195393323.001.0001).

Metzger, E. (1977): "Rabbí Haninah, son of Gamaliel the Nasi of Israel”, Nezir Echav 3, 163-180.

Mildenberg, L. (1984): The Coinage of the Bar Kokhba War (=Typos 6), Frankfurt.

Milik, J. T. (1953): “Une lettre de Siméon Bar Kokhba”, Revue Biblique 60, 276-294.

Miller, S. S. (1996): "Hellenistic and Roman Sepphoris: The Historical Evidence”, [en] R. M. Nagy et alii (eds.), Sepphoris in Galilee: Crosscurrents of Culture, Winona Lake.

Mor, M.

(1985): “The Bar Kokhba Revolt and non-Jewish Participants”, Journal of Jewish Studies 36, 200-209.

(2016): The Second Jewish Revolt. The Bar Kokhba War, 132-136 CE (=The Brill Reference Library of Judaism 50), Leiden-Boston (https://doi.org/10.1163/9789004314634).

Mount, Ch. (2002): Pauline Christianity: Luke-Acts and the Legacy of Paul (=Novum Testamentum, Supplements 104), Leiden-Boston (https://doi.org/10.1163/9789047401377).

Muñiz, E.

(2006): Himnos a Isis, Madrid.

(2009): "The Cult of the Egyptian Gods in Roman Athens", [en] C. Bonnet - V. Pirenne - D. Praet (éds.), Les religions orientales dans le monde grec et romain: Cent ans après Cumont (1906-2006). Bilan historique et historiographique, Colloque de Rome, 16-18 Novembre, 2006 (=Études de philologie, d'archéologie et d'histoire anciennes 45), Bruxelles-Rome.

(2011): "Isis, diosa del Nilo y del mar", [en] E. Ferrer - M C C. Marín - A. Pereira (coords.), La religión del mar. Dioses y ritos de navegación en el Mediterráneo antiguo (=SPAL, Monografías 16), Sevilla, 145-154.

Nashrallah, L. (2008): “The Acts of the Apostles, Greek Cities, and Hadrian's Panhellenion", Journal of Biblical Literature 127/3, 533-566.

Nötscher, F. (1961): "Bar Kochba, Ben Kosba: der Sternsohn, der Prächtige", Vetus Testamentum 11, 449-451.

Núñez, J. (2002): El Evangelio en Antioquía. Gál 2, 15-21 entre el incidente antioqueno y la crisis gálata (=Plenitudo temporis. Estudios sobre los orígenes y la antigüedad cristiana 7), Salamanca.

O’Neill, J. C. (1961): The Theology of Acts in Its Historical Setting, London.

Oppenheimer, A.

(1980): The Bar Kokhba Revolt, Jerusalem.

(2003): "The Ban on Circumcision as a Cause of the Revolt: A Reconsideration", [en] P. Schäfer (ed.), The Bar Kokhba War Reconsidered. New Perspectives on the Second Jewish Revolt against Rome (=Texte und Studien zum antiken Judentum 100), Tübingen, 55-67.

Peleg, Y. (2011): “On the Date of the 'Redemption of Israel' in the Documents of the Judaean Desert”, New Studies on Jerusalem 17, 369-383.

Penner, T. (2004): In Praise of Christian Origins. Stephen and the Hellenists in Lukan Apologetic Historiography (=Emory Studies in Early Christianity), New York.

Perea, S.

(2001): Entre Occidente y Oriente. Temas de Historia romana: Aspectos religiosos (=Signifer Libros. Graeco-Romanae Religionis Electa Collectio 4), Madrid. 
(2003): "Los últimos años de Trajano y los judíos de Oriente”, [en] J. Alvar - J. Ma Blázquez (eds.), Trajano, Madrid, 173-187.

Pervo, R. I. (2006): Dating Acts: Between the Evangelist and the Apologist, Santa Rosa.

Qimron, E. (1986): The Hebrew of the Dead Sea Scrolls (=Harvard Semitic Studies 29), Atlanta.

Rabello, A. M. (1975): “The Ban on Circumcision as a Cause of the Bar Kokhba's Rebellion", Israel Law Review 29, 176-214 (http://dx.doi.org/10.1017/S002122370001462X).

Rius Camps, J. (1989): De Jerusalén a Antioquía. Génesis de la Iglesia cristiana. Comentario lingüistico y exegético a Hch 1-12, Córdoba.

Ruiz, D.

(1954): Padres Apologetas, Madrid.

(1993): Padres Apostólicos, Madrid.

Salomies, O. (1985): "Die Herkunft der senatorischen Tineii”, Zeitschrift für Papyrologie und Epigraphik 60, 199-202.

Sar-Avi, D. (2002): Place Names in the Documents of the Roman Period Found in the Judean Desert, Tesis doctoral, Universidad Bar Ilan, Ramat Gan (en hebreo).

Sartre, M.

(1991): L'Orient romain. Provinces et sociétés provinciales en Méditerranée orientale d'Auguste aux Sévères (31 av. J.C.-235 apr. J.C.), Paris.

(1997): Le Haut-Empire romain. Les provinces de Méditerranée orientale d'Auguste aux Sévères (31 av. J.C.-235 apr. J.C.), Paris.

Schäfer, P.

(1990): “Hadrian's Policy in Judea and the Bar Kokhba Revolt: A Reassessment", [en] Ph. R. Davis - R. T. White (eds.), A Tribute to Geza Vermes: Essays on Jewish and Christian Literature and History (=Journal for the Study of the Old Testament. Supplement Series 100), Sheffield, 281-303.

(1999): "The Bar Kokhba Revolt and Circumcision: Historical Evidence and Modern Apologetics", [en] A. Oppenheimer (Hrsg.), Jüdische Geschichte in hellenistisch-römischer Zeit, München, 119-132.

Shellard, B. (2002): New Light on Luke. Its Purpose, Sources and Literary Context (=Journal for the Study of the Old Testament. Supplement Series 215), London-New York.

Sherwin-White, A. N. (1966): The Letters of Pliny. A Historical and Social Commentary, Oxford.

Stemberger, G. (1979): "Die Beurteilung Roms in der Rabbinischen Literatur", Aufstieg und Niedergangderrömischen Welt II, 19/2,361-364(http://dx.doi.org/10.1515/9783110839043007).

Swain, S. (2003): Hellenism and Empire: Language, Classicism and Power in the Greek World AD 50-250, Oxford.

Syme, R.

(1971): Emperors and Biography. Studies in the Historia Augusta, Oxford.

(1962): “The Wrong Marcius Turbo", Journal of Roman Studies 52, 87-96 (http://dx.doi. org/10.2307/297879).

Tepper, Y. - Di Segni, L. (2006): A Christian Prayer Hall of the 3rd Century CE at Kfar 'Othnay (Legio). Excavations at the Meggido Prison 2005, Jerusalem.

Theicher, J. L. (1953): "Documents of the Bar Kokhba Period”, Journal of Jewish Studies 4, 133-134.

Tyson, J. B. (2006): Marcion and Luke-Acts. A Defining Struggle, Columbia.

Vana, L. (2001): “La birkat ha-minim è una preghiera contro i giudeocristiani?", [en] G. Filoramo - C. Gianotto (curs.), Verus Israel. Nuove prospettive sul giudeocristianesimo. Atti del Colloquio di Torino (4-5 novembre 1999), (=Biblioteca di cultura religiosa 65), Brescia, 147-189.

Walsh, P. G. (ed. \& trans.), (2006): Pliny the Younger. Complete Letters, Oxford. 
Yadin, Y. - Greenfield, J. C. - Yardeni, A. - Levine, B. (2002): The Documents from the Bar Kokhba Period in the Cave of Letters: Hebrew, Aramaic and Nabatean Papyri (=Judean Desert Studies 2), Jerusalem.

Yeivin, S. (1955): "Some Notes on the Documents from Wadi Murabba'at dating from the Days of Bar Kokhba", 'Atiqot 1, 95-108.

Zeitlin, S. (1973-1974): "Who were the Galileans? New Light on Josephus' Activities in Galilee”, Jewish Quartely Review 64, 189-203 (http://dx.doi.org/10.2307/1454129). 